\title{
Self-Healing Systems on Anodes for Next Generation Energy Storage Devices
}

\author{
Neslihan Yuca ${ }^{1,2^{*}}$, Ilknur Kalafat $^{1}$, Emre Guney $^{1}$, Busra Cetin ${ }^{1}$, Omer S. Taskin ${ }^{1,3^{*}}$ \\ ${ }^{1}$ Enwair Energy Technologies Corporation, Maslak, 34469 Istanbul, Turkey \\ ${ }^{2}$ Department of Electric-Electronic Engineering, Maltepe University, Maltepe, 34857 Istanbul, Turkey \\ ${ }^{3}$ Department of Chemical Oceanography, Institute of Marine Science and Management, Istanbul University, 34134 \\ Istanbul, Turkey \\ *Corresponding authors: nyuca@enwair.com,omersuat@enwair.comlomert@istanbul.edu.tr
}

\begin{abstract}
Self-healing is the capability of materials to repair themselves after damage has occurred, usually by interaction between molecules or chains. Physical and chemical processes are applied for the preparation of self-healing systems. There are different approaches for these systems such as heterogeneous systems, shape memory effects, hydrogen bonding or covalent-bond interaction, diffusion and flow dynamics. Self-healing mechanisms can occur in particular by heat and light exposure or by reconnection without direct effect. The applications of these systems display an increasing trend in both R\&D and industry sectors. Moreover, self-healing systems and their energy storage applications are currently getting great importance. This review aims to provide general information on recent developments in self-healing materials and their energy applications in view of the critical importance of self-healing systems for lithium-ion batteries (LIBs). In the first part of the review, an introduction about self-healing mechanisms and design strategies of self-healing materials is given. Then, selected important healing materials in the literature for the anodes of LIBs are mentioned in the second part. The results and future perspectives are stated in the conclusion section.
\end{abstract}

Keywords: self-healing; polymers; batteries; silicon anodes 
$\beta$-CD $\quad: \beta$-cyclodextrin nanogels

AMPS : 2-Acrylamido-2-methylpropanesulfonic acid

AN : acrylonitrile

Ad : adamantanes

BA : acrylic acid n-butyl ester

BMI : 1,6-bismaleimide

CBA : 4-carboxybenzaldehyde

CE : Coulombic efficiency

CMC : carboxymethyl cellulose

CPAM : cationic polyacrylamides

DC : discharge capacity

DEC : diethyl carbonate

DMC : dimethyl carbonate

D-A : Diels-Alder

EC : ethylene carbonate

EMC : ethyl methyl carbonate

FEC : fluoroethylene carbonate

FE : fully esterification

FPAA : furfurylamine-functionalized poly(acrylic acid)

Ga-In-Sn : gallium-indium-tin alloy

GCS : glycol chitosan

HB : hydrogen bonded

IC : Ionic conductivity

ICE : initial coulombic efficiency

$\mathrm{LiPF}_{6} \quad$ : lithium hexafluorophosphate

LM : Liquid Metal

OSA : oxidized alginate

PEDOT : poly (3, 4-ethylene- dioxythiophene)

PSS : poly (styrenesulfonate)

PEGMA : poly (ethylene glycol) methyl ether methacrylate

PAA : polymer poly(acrylic acid) 
PVA : polyvinyl alcohol

PE : partially esterification

PEG : polyethylene glycol

PEGA : poly (ethylene glycol) methyl ether acrylate

RT : room temperature

TPU : thermoplastic polyurethane

UPy : : ureido-pyrimidinone

UPyMA : (2-(3-(6-methyl-4-oxo-1,4-dihydropyrimidin-2-yl)ureido)ethyl methacrylate)

VC : vinyl carbonate 


\section{Introduction}

The use of composite materials is increasing day-by-day. The composite materials have gradually increased in studies carried out in the aviation industry, where technological processes are rapidly adapted and which is important in the technologies development. With the development of technology, the ability of composite materials to adapt to the conditions of their environments and to respond appropriately to these conditions is also important. These materials, called smart materials, develop stimuli in a way that changes their mechanical, electrical, optical or magnetic properties in response to external stimuli. The production of such smart materials leads to the emergence of research topics such as increasing the durability of use, prolonging their life and/ or reducing the cost of healing, and engineers do many studies on these issues. In fact, this can be achieved by a perfect mechanism called self-healing in biological systems. In order to apply this mechanism to materials, biological systems are studied and tried to be imitated. In this context, studies on new generation smart materials have created a new research area called self-healing materials, and research in this area continues rapidly. Thanks to this behavior, it is argued that the life and reliability of materials that are defective due to production or damaged as a result of an external effect can be increased, and thus healing costs can be reduced [1-7].

Self-healing can be defined as the ability of a material to heal (recover/repair) damages automatically and autonomously without any outside intervention. Many general terms are used to describe such a property in materials, such as self-healing, autonomic healing, and autonomic heal. When self-healing properties are added to man-made materials, often the self-healing action cannot be performed without an external trigger. There are several systems used to impart self-healing ability to materials (Figure 1). These systems can be grouped into two main groups as capsulebased healing (bead, fiber and/or vascular type and mechanochemical), which is basically autonomous, and healing by the action of non-autonomous external stimuli [1, 8-13]. 


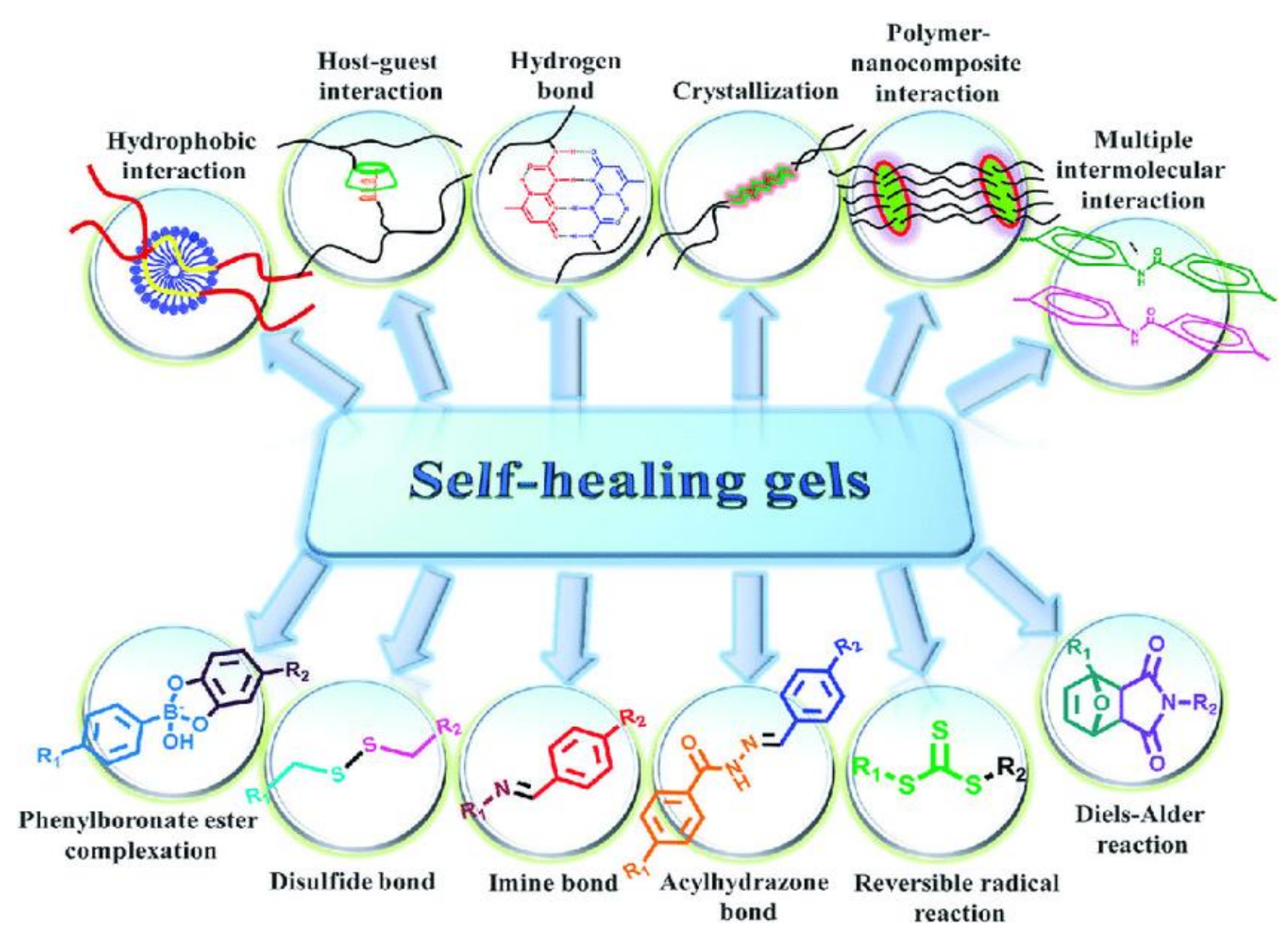

Figure 1. Self-healing systems Copyright Elsevier 2012 [7]

Capsule-based healing systems involve microencapsulations and are the process of protecting micron-sized solid particles, liquid droplets or gas by isolating them from the external environment with an inert shell. The capsule ensures that the healing agent is retained within the system until a break or crack occurs in the self-healing materials (Figure 2). In capsule-based heal systems, interfacial, in-situ, co-acidification, soluble solution encapsulation techniques are among the most basic techniques. Self-healing occurs using microencapsulated healing agents and catalytic chemical triggers in the epoxy matrix. In this system, with the progression of the crack, the embedded microcapsules are disintegrated and the healing agent advances to the crack plane by capillary action. The polymerization of the healing agent is triggered by contact with the catalysts embedded in the epoxy, causing the cracked surfaces to bond together. Thus, the injury-induced trigger mechanism provides region-specific autonomic healing control. The biggest disadvantage of microcapsule-based self-healing systems is the limited number of healing agents, and it is not known when the healing agent will be completely depleted, especially locally, in cases of multiple 
healing. Multiple healing is only possible if there is an excess of healing agents in the matrix after the first healing has taken place [1, 14-17].

Other examples of autonomic self-healing systems are fiber and vascular systems. Fiber and/or vascular self-healing systems are designed from fibers (hollow fiber) or hollow reticulated structures. In these systems, the healing agents are stored in the spaces inside the fiber or reticular structures until damage occurs and are released in case of damage. In systems consisting of hollow fibers, channeled glass hollow fibers (HGFs) with a diameter of about $60 \mu \mathrm{m}$ are filled with the appropriate healing agent. Hollow fibers are used as polymer additives in one, two and three dimensions. In the region where the crack occurs, the resin and curing agent in the fibers flow into the polymer matrix and polymerize, and as a result, they allow the closure of the crack. Although hollow fibers placed in one dimension seem to be advantageous due to their ease of manufacture, their self-healing capabilities are limited compared to other designs [10, 18-23].

In vascular network systems, on the other hand, since there are multiple connection points at any point, a higher amount of healing agent reaches the damaged area and causes an increase in mechanical healing reliability. When there is damage to the human skin, blood flow is triggered from the capillaries in the reticulated structure to the damaged part and coagulation occurs rapidly. Due to the vascular nature of this feeding system, minor injuries in the same area can be healed repeatedly. On the other hand, the production process of such systems is complex and it is very difficult to obtain synthetic materials with such meshes for practical applications.

\section{a) Intrinsically self-healing polymer systems with reversible chemical bonds}
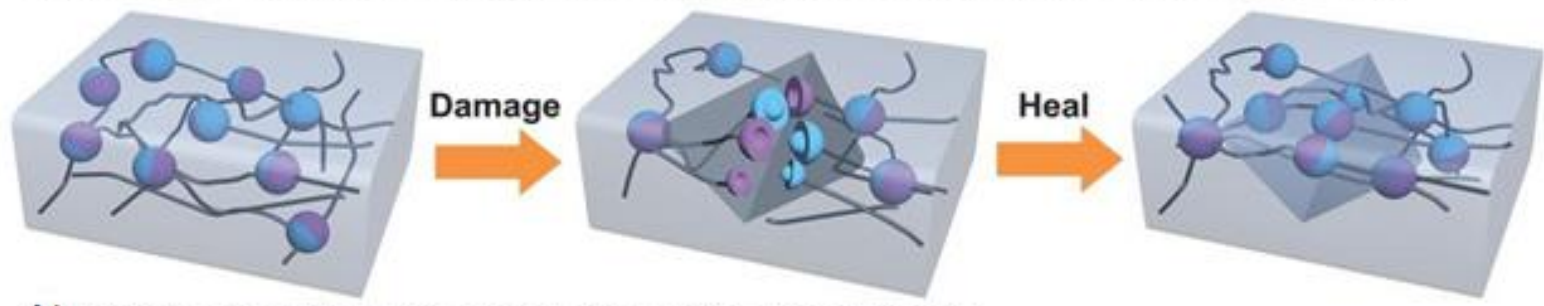

b) Self-healing through exhaustion of healing agents
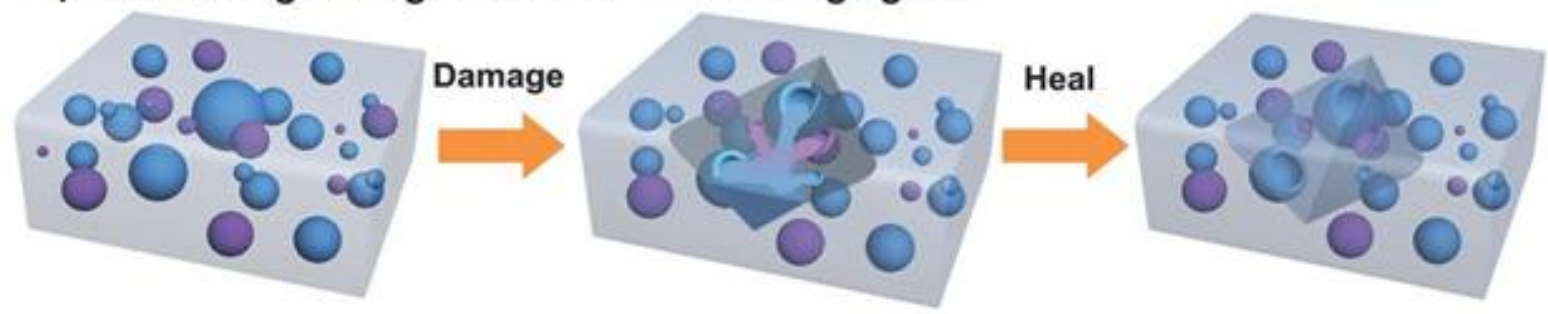

Figure 2. Intrinsically capsulated self-healing systems Copyright Wiley, 2009 [7] 
The other method used to gain self-healing ability is non-autonomous mechanisms and occurs through latent effects that allow self-healing of damages. Non-autonomous heal process; The thermally reversible reactions occur with the soluble thermoplastic phase dispersed in the polymer, molecular diffusion, ionomeric rearrangements and supramolecular heal mechanisms. Supramolecular self-healing polymers are designed with multiple complementary, reversible bonds to form strong end groups and/or side groups, resulting in self-healing polymers as a result of manufacture [24-28].

Supramolecular polymers have gained an important place in the field of self-healing polymers in recent years. Supramolecular polymers, which emerged with the combination of polymer science and supramolecular chemistry, have created a rapidly developing interdisciplinary research field. Broadly speaking, the term "supramolecular polymers" can be defined as any type of coupling formed from one or more molecular components via reversible bonds. However, if a more limited and clear definition is needed, supramolecular polymers result in the emergence of polymeric properties in solutions and solids; It can be defined as polymeric arrays of monomeric units held together by highly directional and non-covalent reversible interactions. These non-covalent interactions in supramolecular systems can be classified as $\pi-\pi$ stacking interactions, metal ligand interactions, ionic interactions, and hydrogen bonds [29-32].

\subsection{Various Approaches of Self-Healing Polymers}

\subsection{1. $\pi-\pi$ Stacking Interactions Based Self-Healing Polymers}

Although $\pi-\pi$ stacking interactions are weaker than hydrogen bonds and ionic interactions, they have an important place in supramolecular systems due to their low probability of degradation by environmental factors such as humidity. The interactions between aromatic rings of different sizes, shapes, and displacement patterns are called $\pi-\pi$ stacking or $\pi-\pi$ interactions. Aromatic $\pi$ interactions first emerged in the early 1980s and have been applied in many fields, especially biological systems, molecular recognition, self-assembly, asymmetric reduction catalyst and organic transistors. The interaction usually occurs between the $\pi$-deficient electron unit and the $\pi$ electron rich unit, and the interaction can occur mainly in two ways; face-to-face stacking and face-to-side stacking. $\pi-\pi$ stacking interactions in self-healing supramolecular polymer materials were first obtained by Burattini et al. by combining polyimide containing multiple $\pi$-electron deficient acceptor sites and siloxane polymer containing $\pi$-electron-rich pyrenyl functional groups. 
In such interactions, the nature of the electron-poor components is critical in terms of interactions, and it also affects the bond strength of the material to be obtained by playing a role in determining the bond strength of the stack [33, 34].

\subsubsection{Metal Ligand-Based Self-Healing Polymers}

In the field of supramolecular chemistry, special attention has recently been paid to metallosupramolecular polymers. Metallo-supramolecular polymers can also work well in a self-healing system. Unlike polymers formed by hydrogen bonds and $\pi-\pi$ stacking interactions, the reversibility and stimulus-response of metallopolymers are directly affected by metal ligand binding resistance. Therefore, the choice of polyvalent metal-ligand interaction is effective in obtaining a stable, dynamic and reversible cross-linked network. In a given field, the specific properties of materials can be altered by changing the ligand and metal [35].

\subsubsection{Ionic Interactions Based Self-Healing Polymers}

Ionic interactions in polymers are mainly manifested by the formation of ionomers. Ionomers can be defined as polymers in which the volumetric properties are governed by ionic interactions in discrete regions of the material. Ionomers; Since they contain ionic, dipole-dipole and/or iondipole bonds, they also occupy an important place among supramolecular self-healing polymer materials. These ionic groups can aggregate together to form a complex, and when ionomers appear in a crack, they can self-heal through these strong intermolecular interactions between the ionic groups. In self-healing polymers, the polymer matrix must provide sufficient mobility to the polymer chains so that ionic interactions can take place at the damaged sites, thus allowing the chains to be intertwined and rearranged. In addition, many factors such as the nature of ionic groups and counter-ions, degree of neutralization, temperature, content of ionic groups and dielectric constant also play an important role in the properties of materials that self-heal by ionic interactions $[14,36]$. 


\subsubsection{Hydrogen Bond Based Self-Healing Polymers}

Among the various self-healing mechanisms in supramolecular polymers, healing by hydrogen bonding has attracted the attention of many research groups because the hydrogen bonds can be easily separated and reconnected at room temperature, and the recovery properties can be easily adjusted by manipulating the number of hydrogen bonds. Self-healing supramolecular polymers contain both covalent and non-covalent bonds in their structure. The basis of damage to materials is the breaking of chemical bonds. In self-healing materials containing hydrogen bonds, hydrogen bonds are easier to break than covalent bonds. When cracks occur as a result of applying external force to a supramolecular polymer, multiple free, unbonded hydrogen bonds are formed at the new interfaces. These free hydrogen bonding parts come together and form new hydrogen bonds, allowing the cracks to close and the damaged areas to heal. However, the activity of free hydrogens can continue for a period of time; The self-healing abilities of the new surfaces will decrease due to the recombination of free hydrogens in the same regions. On the other hand, the reduced selfhealing property can be significantly increased by the heat treatment applied to the fracture surfaces $[18,37,38]$.

Most of the work on self-healing constitutes research on understanding and improving mechanisms. In this section, studies on the supramolecular healing mechanism are mentioned and mostly self-healing systems through reversible hydrogen bonding, which is the main subject of this research, are included. Cordier et al. used reversible hydrogen bonds to form supramolecular self-healing rubber. They took advantage of the natural recycling of hydrogen bonds and the bond orientation that allows the chains in the network structure to self-assemble. A mechanical stimulus is needed to initiate the healing of the material obtained by Cordier et al., and the polymer structure is brought together by contacting the damaged surfaces. Thus, hydrogen bonds are allowed to form the reticulated structure. Hydrogen bond formation in this material was provided by amidoethyl imidazolidone and diaminoethyl urea groups, and it was observed that no crystalline region was formed during self-healing. It has been reported that the material produced by this method elongates up to the breaking point with $500 \%$ strain. In addition, it has been explained that less than $5 \%$ residual stress is seen with the removal of the applied force and it has the capacity to recover after $300 \%$ strain. The result in tests for damage and healing in rubber is that the specimens self-heal over time at room temperature when cut into two pieces and then re-contacted. It has been emphasized that the healeded sample can be deformed up to $200 \%$ without breaking with a contact 
time of 15 minutes. It was also stated that the amount of recovery in the materials decreased as the time elapsed before reassembling the damaged surfaces. With this mechanical intervention, it has been proven by the tests that the healing cycle can be successfully performed many times by contacting the broken or broken parts without using any chemicals [13, 38-44].

\subsection{Effect of Nanoparticle Additive on Self-Healing Properties}

In the literature, nanoparticle doping has been done to increase the healing properties of selfhealing systems. The healing process in nanoparticle-doped polymers does not consist of steps such as breaking or recombining polymer chains. As cracks and defects occur, nanoparticles dispersed in the polymer phase fill the cracked or damaged part. Firstly, Lee et al. combined computer simulation with micromechanics to demonstrate the self-healing effect of nanoparticles in polymers, and conducted research on multilayer composites produced [45]. It has been observed that such polymer-nanoparticle composites actively respond to damage and potentially multiple self-healing of the polymer system as long as the nanoparticles continue to exist in the system. In another publication, they modeled the functionality of applied nanocomposite coatings to heal nanoscale defects on the surface with molecular dynamics and lattice spring simulations. The modeling results showed that nanoparticles tend to migrate to the damaged areas with a polymerinduced attraction force, that small particles are more effective in healing the damaged area than large particles, and that small particles are transported to the damaged area in a shorter time interval. Gupta et al. experimentally proved the transport and aggregation of nanoparticles around cracks in multilayer composite structures in the simulation studies in the literature. In the study, $3.8 \mathrm{~nm} \mathrm{CdSe} / \mathrm{ZnS}$ nanoparticles were embedded in the $\mathrm{SiO}_{2}$ layer (50 nm) deposited on the PMMA film $(300 \mathrm{~nm})$, and it was observed that the nanoparticles in the fragile $\mathrm{SiO}_{2}$ layer were transported to the polymer phase along the crack. It is stated that the transport of nanoparticles depends on the enthalpic and entropic interactions between the PMMA matrix and the nanoparticles. As a result of the TEM analysis applied to the cross-sectional area of the composite material, it was observed that nanoparticles whose surface was modified with fluorescent PEO ligands were deposited on the interface of PMMA and $\mathrm{SiO}_{2}$ layers. The place of nanoparticles in the self-healing phenomenon is explained by the stretching and stretching movements of the polymer chains close to the damaged area, and the tendency to decrease the nanoparticle-polymer interaction with the accumulation of nanoparticles in the crack and pre-crack regions is stated to be the driving force [46]. 


\section{Recently Reported Self-Healing Anode Systems}

\subsection{Physical Interaction based Self-Healing Materials}

For self-healing materials that can exhibit reversible properties, there were originally two noncovalent approaches, hydrogen bonding and $\pi-\pi$ stacking $[2,47]$. In addition, Harada et al. hostguest molecular gels have been applied in macroscopic self-healing [48]. Nakahata et al showed supramolecular materials that have self-healing properties and induce a sol-gel phase transition through host-guest interactions provided with poly(acrylic acid) (pAA) possessing $\beta$-CD as a host polymer with pAA possessing ferrocene as a guest polymer [49]. Kakuta et al reported Supramolecular hydrogels with $\beta$-cyclodextrin and adamantane guest molecules mend by a hostguest interaction show self-healing features [50]. Deng et al. Synthesized curable cross-linked polymer gels under acidic conditions with reversible covalent acylhydrazone bonds [51]. Matyjaszewski and colleagues reported trithiocarbonate units activated by external stimuli in their structures for the synthesis of self-healing cross-linked polymers and gels [52, 53]. Lehn and colleagues investigated new Diels-Alder self-healing materials that exhibit structural transformation in the absence of external stimuli [54]. Scaiano and et al showed DABBF that works as a dynamic covalent bond autonomously self-healing [55]. Fox et al reported reinforced with cellulose nanocrystals to afford a healable nanocomposite material that supramolecular polymer mixture formed through $\pi-\pi$ interactions [33]. Ying et al reported nitrogen-bound urea and their use to make polyureas and poly(urethane-urea) capable of catalyst-free dynamic property change and auto-repair at low temperature [24]. For the first time, a self-assembled supramolecular gel of metal-ligand and polypyrrole hydrogel with high conductivity and a hybrid gel based on nanostructured polypyrrole [35]. Li et al reported a self-healing network crosslinked by coordination complexes that it consists of ligands via both nitrogen and oxygen atoms of the carboxamide groups. in room conditions [28]. Firstly, Yan and colleagues demonstrated that such a synthetic hydrogel material is prepared from polyethylene glycol and polyethyleneimine that exhibit self-healing abilities. [56]. Nishimura at all demonstrated incorporated networks of silyl ether linkages into covalently cross-linked polymer reprocessability [57]. Urban et al demonstrated that commodity copolymers, such as poly(methyl methacrylate)/n-butyl acrylate [p(MMA/nBA)] and their derivatives, can self-heal upon mechanical damage with the key and lock commodity self-healing behavior [6]. $\mathrm{Zn}^{2+}$-imidazole crosslinks are distributed in a hydrogen bonded/DielsAlder dynamic covalent double crosslinked network, ideal sea cucumber inspired materials that 
can transform into tough but tough materials after exposure to external stimuli and better resist external influences In contrast to moisture-affected non-covalent crosslinks SCIMs with reversible self-healing system have been reported [26].

\subsubsection{Hydrogen bonded supramolecular self-healing}

Phase separation effects at polymeric interfaces are also determinants of self-healing. Kovalenko et al. showed that Sodium Alginate (Algae) Binder instead of PVdF. In contrast to PVdF, NaAlg contains carboxyl groups that have hydrogen bonds to the oxidized Si surface. This self-healing binder prevents the volume expansion with these bonds during lithation/delithation. $t$ is the first example of the use of algae as a binder for the Si anode, which exhibits a capacity of $1700 \mathrm{~mA}$ h1 after 100 cycles at $4200 \mathrm{~mA} \mathrm{g-1}[58,59]$. The electrode material developed with the self-healing binder proposed by Wang shows a more stable cycling performance with a capacity of up to 2000 mA h g100 cycles at a current density of $0.4 \mathrm{~A} \mathrm{~g}^{-1}$ [60]. Yue et al improved Carboxymethyl chitosan for $\mathrm{Si}$ anode of $\mathrm{Li}$-ion batteries that show in figure $4 \mathrm{a}$. This water soluble binder shows a high first discharge capacity $4270 \mathrm{mAh} \mathrm{g}^{-1}$ with a first coulombic efficiency of $89 \%$ [61]. Chen et al. provide the 3D spatial distribution of Self-healing polymer to Silicon nanoparticles with the interaction of hydrogen bonds and healed cracks by the interaction between polymer and Silicon that show in figure 3a [62]. Self-healing polymers with a high Silicon nanoparticle filling cycling stability of trifunctional crosslinked polymer electrodes showed 3-4 mAhcm-2 aerial capacity and 140 cycles [29]. Sun et al. reported the flexible carbon/Si foam material that is shown in figure $4 \mathrm{~d}$ and coated it with polymer that self-healing functionalization with covalent and hydrogen bonds. The thickness of the self-healing polymer coating on the electrode was affecting the percent of strain and electrochemical capacity of the cell. Each time the polymer coating on the carbon/Si electrode was increased by $2 \mathrm{X}$, the strain increased by a factor of 2 , while the capacitance resulted in $722 \mathrm{mAhg}^{-1}$ and $584 \mathrm{mAhg}^{-1}$ at the $100^{\text {th }}$ cycle, respectively. It was determined that more coating caused a rapid capacity fading [63]. The dual crosslinking polymer that shown in figure $4 \mathrm{f}$ heals visible cracks on the electrodes and no obvious delamination between electrode surface and copper foil is proposed by Gendensuren and Oh [64]. 


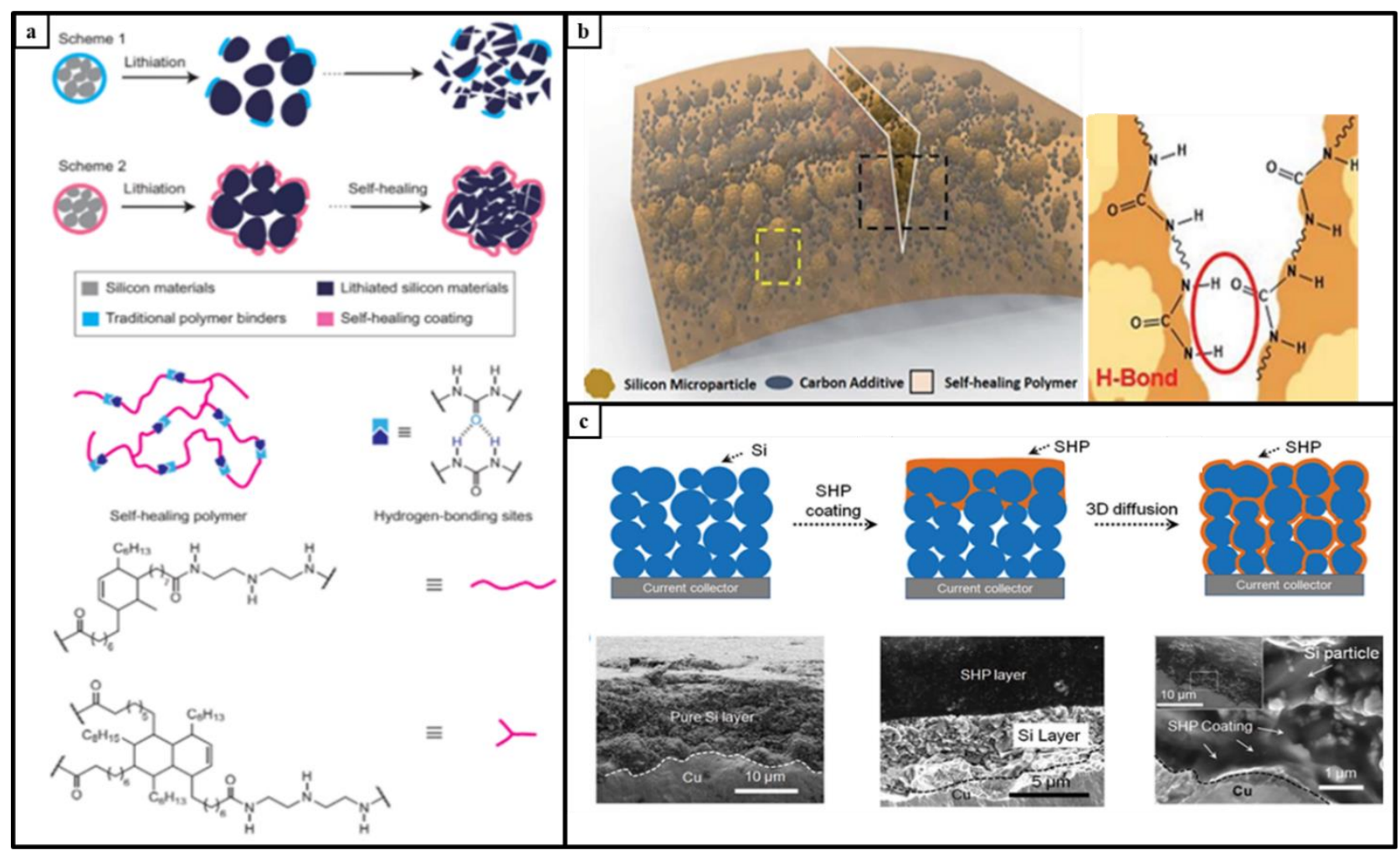

Figure 3. a. Mechanism of the self-healing polymer,Reprinted with permission from 60, Copyright 2015, Advanced Energy Materials. b. Schema of the self-healing electrode with a homogenous distribution of Silicon microparticles and self-healing polymer with hydrogen bond, Reprinted with permission from 69, Copyright 2018, Royal Society of Chemistry. c. Schema of Silicon anode with self-healing polymer and SEM images of Silicon anode with self-healing polymer coating, Reprinted with permission from 62, Copyright 2015, Advanced Energy Materials.

Zhang et al. improved the self-healing ability of Si electrodes. Reconstruction of the crosslinked PAA-UPy network shown in Figure 4 on a Si composite anode using PAA-UPy binder gave an initial discharge capacity of $4194 \mathrm{mAh} / \mathrm{g}$ at $0.5^{\circ} \mathrm{C}$. It retained about $85 \%$ of the capacity in the long cycle. The self-healing PAA-UPy binder improved the electrochemical performance. They preferred using an ureidopyrimidinone functionalized polyethylene glycol. This binder has important properties that resistant large volume expansion and heal cracks [37]. Zhang et al. reported a cyclic solid mesh binder for high performance Si-based anodes. They took advantage of interactions of cationic polyacrylamides (CPAM) and carboxymethyl cellulose (CMC). Prepared electrodes with this composite binder that shown in figure 4 protected the electrochemical capacity of $1906.4 \mathrm{mAh} / \mathrm{g}$ after 100 cycles [67]. Hu et al. fabricated a self-healing gel (figure 4) 
by mixing PEDOT:PSS polymer and poly(vinyl alcohol) with a conductive network. After modification with 4-carboxybenzaldehyde (CBA), formed hydrogen bonds. The half-cell of prepared electrodes with this binder showed a capacity of $1786 \mathrm{mAh} / \mathrm{g}$ at $500 \mathrm{mAg}^{-1}$ at 200 cycles [68]. Kim used a self-healing polymer (figure 3) that serve volume expansion silicon that are homogeneously messy and buried. The electrode exhibit performance $2100 \mathrm{mAhg}^{-1}$ after 100 cycles at $\mathrm{C} / 10$ rate [69].

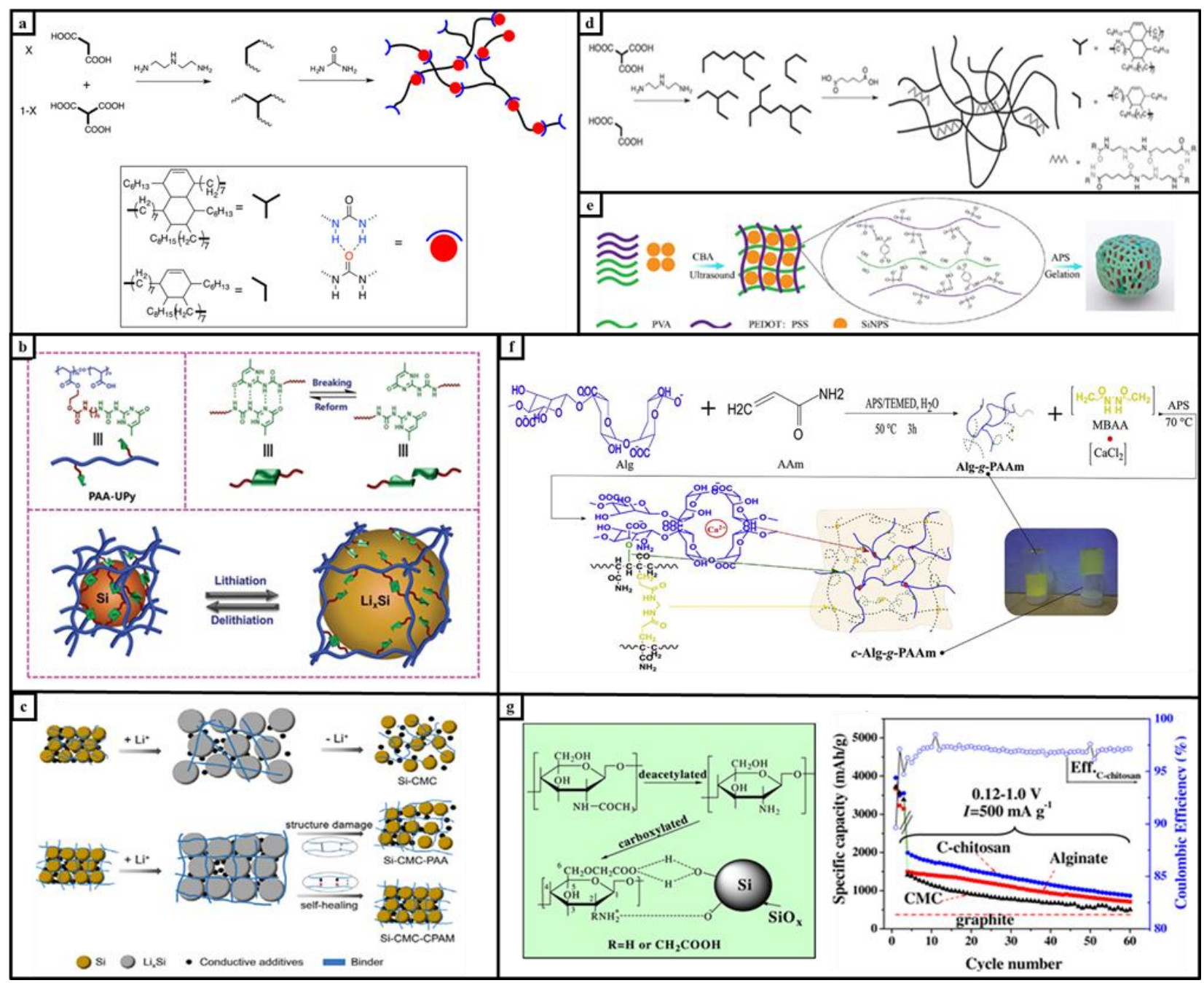

Figure 4. a. Synthesis of self-healing polymers with hydrogen bonds, Reprinted with permission from 29, Copyright 2016, ACS Applied Materials \& Interfaces. b. Structure of PAA-UPy binder and dimers bottomed on quadruple hydrogen bond and the shema of large volume expansion of silicon particles, Reprinted with permission from 37, Copyright 2018, Advanced Science News. c. Mechanism with CMC binder, crosslinked CMC-PAA binder and self-healing CMC-CPAM binder, Reprinted with permission from 67, Copyright 2020, Elsevier. d. Synthesis of the self- 
healing polymer, from 63 Copyright 2019, Advanced Materials. e. Schema of Silicon anode with self-healing conductive hydrogel binder, Reprinted with permission from 68, Copyright 2020, Elsevier. f. Synthesis of dual crosslinking polymers, from 64, Copyright 2019, Journal of Power Sources. g. C-chitosan/Si nanoparticles surface structure and the capacity-cycle graph of Silicon anode with CMC, C-chitosan, Alginate, Reprinted with permission from 61, Copyright 2014, Journal Power Source.

Table 1. Some self-healing materials for hydrogen bond interaction self-healing mechanism

\begin{tabular}{|c|c|c|c|c|}
\hline $\begin{array}{l}\text { Self-healing } \\
\text { material }\end{array}$ & Anode Active materials & Electrolyte & Electrochemical performance & Ref. \\
\hline Na-alginate & Si-C composite anodes & $\begin{array}{l}1 \mathrm{M} \mathrm{LiPF}_{6} \text { in } \\
\mathrm{EC} / \mathrm{DEC} / \mathrm{EMC}\end{array}$ & $\begin{array}{l}2850 \mathrm{mAh} / \mathrm{g}, 0.1 \mathrm{~A} / \mathrm{g} \text { [First } \\
\text { cycle capacity] }\end{array}$ & {$[58]$} \\
\hline PAAH0.2Na0.8 & Si/graphite <100nm & $\begin{array}{l}1 \mathrm{M} \mathrm{LiPF}_{6} \text { in } \\
\mathrm{EC} / \mathrm{DEC} / \mathrm{EMC}\end{array}$ & $\begin{array}{l}50 \mathrm{mAh} / \mathrm{g}, 1100 \mathrm{mAh} / \mathrm{g} \text { at } \\
30 \text { cycles }\end{array}$ & {$[70]$} \\
\hline $\begin{array}{l}\text { Self healing } \\
\text { polymers } \\
\text { (SHPs) }\end{array}$ & $\begin{array}{l}\text { Silicon } \\
\text { microparticle } \\
\text { (SiMP) }\end{array}$ & $\begin{array}{l}1 \mathrm{M} \mathrm{LiPF}_{6} \text { in } \\
\mathrm{EC} / \mathrm{DEC} / \mathrm{EMC}\end{array}$ & $\begin{array}{l}2617 \mathrm{mAh} / \mathrm{g}, 430.4 \mathrm{~A} / \mathrm{g} 80 \% \text { at } \\
90 \text { cycles }\end{array}$ & {$[60]$} \\
\hline $\begin{array}{l}\text { Carboxymethyl } \\
\text { chitosan }\end{array}$ & Silicon & $\begin{array}{l}1 \mathrm{M} \mathrm{LiPF} 6 \text { in } \\
\mathrm{EC} / \mathrm{DEC} / \mathrm{EMC}\end{array}$ & $\begin{array}{l}950 \mathrm{mAh} / \mathrm{g} \text { at } \\
500 \mathrm{~mA} / \mathrm{g} \text { over } 50 \text { cycles. }\end{array}$ & {$[61]$} \\
\hline $\begin{array}{l}\text { Self healing } \\
\text { polymers } \\
\text { (SHPs) }\end{array}$ & $\begin{array}{l}\text { Silicon } \\
\text { microparticle } \\
\text { (SiMP) }\end{array}$ & $\begin{array}{l}1 \mathrm{M} \mathrm{LiPF}_{6} \text { in } \\
\mathrm{EC} / \mathrm{DEC} / \mathrm{VC} / \mathrm{FEC}\end{array}$ & $\begin{array}{l}2736 \mathrm{mAh} / \mathrm{g} \text { at } \mathrm{C} / 20 ; 80 \% \\
\text { retained after } 500 \text { cycles }\end{array}$ & {$[62]$} \\
\hline $\begin{array}{l}\text { Self-healing-type } \\
\text { binder PAABS } \\
\text { Content binder } \\
\text { 9 PAABS+6 } \\
\text { CMC }\end{array}$ & $\begin{array}{l}\text { Silicon 20-30 nm /graphite } \\
\text { electrode }\end{array}$ & $\begin{array}{l}1 \mathrm{M} \mathrm{LiPF}_{6} \text { in } \\
\mathrm{EC} / \mathrm{DEC} / \mathrm{EMC}\end{array}$ & $\begin{array}{l}1150 \mathrm{mAh} / \mathrm{g} 0.5 \mathrm{C} \\
\text { About } 500 \mathrm{mAh} / \mathrm{g} \\
\text { at } 50 \text { cycles }\end{array}$ & {$[71]$} \\
\hline $\begin{array}{l}\text { Native-XG, Na- } \\
\text { CMC, Alginate }\end{array}$ & Si/graphite & $\begin{array}{l}1 \mathrm{M} \mathrm{LiPF}_{6} \text { in } \\
\mathrm{EC} / \mathrm{DEC} / \mathrm{EMC}\end{array}$ & $\begin{array}{l}14.2 \%, 22.8 \%, \text { and } \\
34.6 \% \text { of capacities after } 200 \\
\text { cycles at } 1 \mathrm{C} \\
\text { respectively }\end{array}$ & {$[72]$} \\
\hline $\begin{array}{l}\text { Urea via hydrogen } \\
\text { bonds }\end{array}$ & $\begin{array}{l}\text { Silicon particles }(\sim 0.9 \\
\text { um). }\end{array}$ & $\begin{array}{l}\text { 1M LiPF6 in } \\
\text { EC/DEC/VC/FEC }\end{array}$ & $\begin{array}{l}1700 \mathrm{mAh} / \mathrm{g} \text { at } \mathrm{C} / 20 ; 80 \% \\
\text { retained after } 175 \text { cycles }\end{array}$ & [29] \\
\hline $\begin{array}{l}\text { Self healing } \\
\text { polymers } \\
\text { (SHPs) }\end{array}$ & Silicon & $\begin{array}{l}1 \mathrm{M} \mathrm{LiPF}_{6} \text { in } \\
\mathrm{EC} / \mathrm{DEC}\end{array}$ & $\begin{array}{l}719 \mathrm{mAh} / \mathrm{g} ; 81 \% \text { retained after } \\
100 \text { cycles }\end{array}$ & [39] \\
\hline $\begin{array}{l}\text { Crosslinked } \\
\text { chitosan } \\
\text { (CS-GA) }\end{array}$ & Silicon 100nm & $\begin{array}{l}1 \mathrm{M} \mathrm{LiPF}_{6} \text { in } \\
\mathrm{EC} / \mathrm{DEC} / \mathrm{EMC}\end{array}$ & $\begin{array}{l}278220500 \mathrm{~mA} / \mathrm{g} \\
1969 \mathrm{mAh} / \mathrm{g} \text { at } \\
100 \mathrm{cycles}\end{array}$ & [73] \\
\hline
\end{tabular}




\begin{tabular}{|c|c|c|c|c|}
\hline $\begin{array}{l}\text { Pyrene- } \\
\text { Poly(acrylic acid)- } \\
\text { Polyrotaxane }\end{array}$ & Silicon & $\begin{array}{l}1 \mathrm{M} \mathrm{LiPF}_{6} \text { in } \\
\mathrm{EC} / \mathrm{DEC} / \mathrm{EMC}\end{array}$ & $\begin{array}{l}82.5 \% \\
\text { after } 150 \text { cycles } \\
\text { at } 0.5 \mathrm{C}\end{array}$ & {$[37]$} \\
\hline $\begin{array}{l}\text { Dual-crosslinked } \\
\text { network binder of } \\
\text { Alginate }\end{array}$ & Silicon/graphite anodes & $\begin{array}{l}1 \mathrm{M} \mathrm{LiPF} 6 \text { in } \\
\mathrm{EC} / \mathrm{DEC} / \mathrm{VC} / \mathrm{FEC}\end{array}$ & $\begin{array}{l}1743 \mathrm{mAh} / \mathrm{g} \text { at } 2000 \mathrm{mAh} / \mathrm{g} \\
74 \% \text { retained after } 200 \mathrm{cycles}\end{array}$ & {$[64]$} \\
\hline PAA-UPy & Silicon & $\begin{array}{l}1 \mathrm{M} \mathrm{LiPF}_{6} \text { in } \\
\mathrm{EC} / \mathrm{EMC} \mathrm{DMC}\end{array}$ & $\begin{array}{l}2000 \mathrm{mAh} / \mathrm{g} \text { at } 1 \mathrm{C} 74 \% \\
\text { retained after } 110 \text { cycles }\end{array}$ & {$[37]$} \\
\hline $\begin{array}{l}\text { UPy functionalized } \\
\text { PEG }\end{array}$ & Silicon & $\begin{array}{l}1 \mathrm{M} \mathrm{LiPF} 6 \text { in } \\
\mathrm{EC} / \mathrm{DMC}\end{array}$ & $1847 \mathrm{mAh} / \mathrm{g} ; 81 \%$ ICE & {$[75]$} \\
\hline$\overline{\text { CMC-CPAM }}$ & Silicon-based & $\begin{array}{l}1 \mathrm{M} \mathrm{LiPF}_{6} \text { in } \\
\mathrm{EC} / \mathrm{DEC} / \mathrm{EMC}\end{array}$ & $2103 \mathrm{mAh} / \mathrm{g}$ at $2 \mathrm{C}, 92 \% \mathrm{ICE}$ & {$[67]$} \\
\hline PEDOT-PSS-PVA & Silicon & $\begin{array}{l}1 \mathrm{M} \mathrm{LiPF}_{6} \text { in } \mathrm{EC} / \\
\mathrm{DEC} / \mathrm{EMC}\end{array}$ & $\begin{array}{l}1743 \mathrm{mAh} / \mathrm{g} \text { at } 2000 \mathrm{mAh} / \mathrm{g} \\
74 \% \text { retained after } 200 \mathrm{cycles}\end{array}$ & {$[68]$} \\
\hline$\overline{\text { PAU-g-PEG, }}$ & Silicon & $\begin{array}{l}1 \mathrm{M} \mathrm{LiPF}_{6} \text { in } \\
\mathrm{EC} / \mathrm{DEC} / \mathrm{EMC}\end{array}$ & $\begin{array}{l}2831 / \\
3.2 \mathrm{mAh} / \mathrm{cm}^{2} 280.1 \mathrm{C} 85 \% \text { at } \\
120 \text { cycles }\end{array}$ & {$[38]$} \\
\hline $\begin{array}{l}\text { Self healing } \\
\text { polymers } \\
\text { (SHPs) }\end{array}$ & $\begin{array}{l}\text { Silicon } \\
\text { microparticle } \\
(\text { SiMP) }\end{array}$ & $\begin{array}{l}1 \mathrm{M} \mathrm{LiPF}_{6} \text { in } \\
\mathrm{EC} / \mathrm{DEC} / \mathrm{EMC}\end{array}$ & $\begin{array}{l}91.8 \% \text { capacity retention after } \\
100 \text { cycles at } \mathrm{C} / 10 \\
2100 \mathrm{mAh} / \mathrm{g}\end{array}$ & {$[69]$} \\
\hline
\end{tabular}

\subsubsection{Metal Interaction Self-Healing Materials}

A self-healing mechanism occurs when a metal atom is attached to the side chains as part of the backbone or to the ends of the polymer chains or coordinated with covalently bonded ligands within the polymer backbone. Liquid metal Gallium (Ga) (figure 5a) was used for the first time by Deshpande et coworkers as a negative electrode with self-healing properties. It has been observed that low melting point liquid metals heal cracks with reversible solid-liquid transition during charge-discharge [76]. 


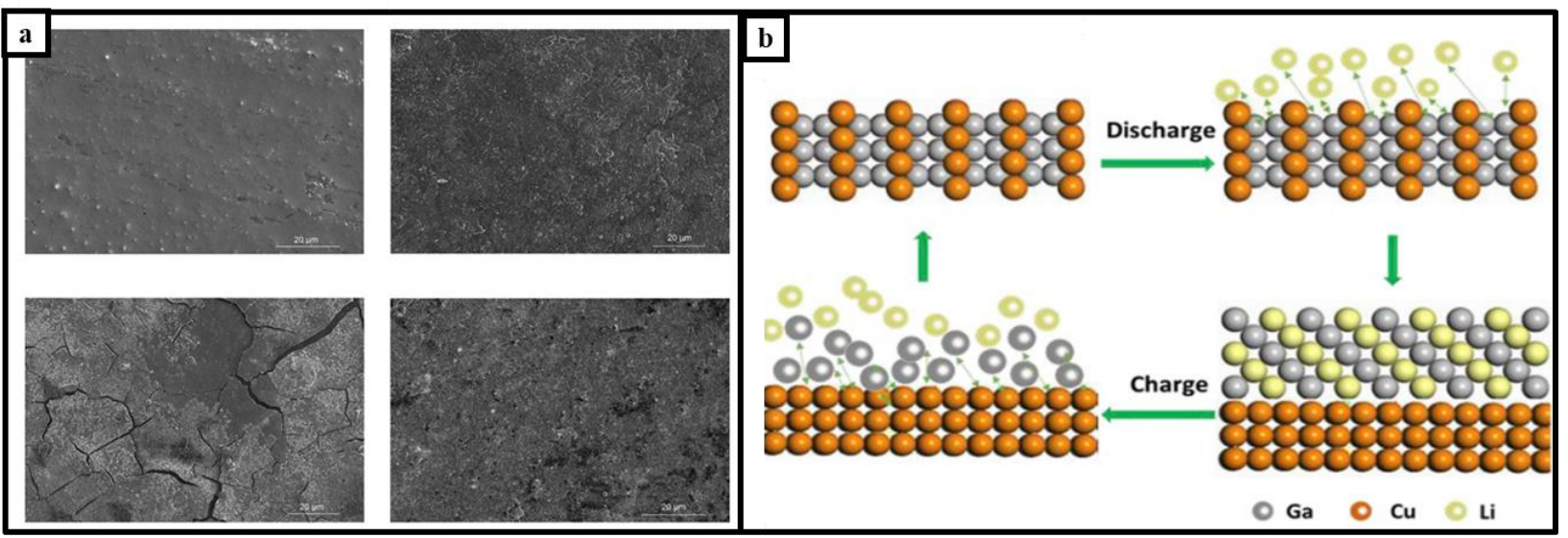

Figure 5. a. Morphology of Ga electrode before cycle, after full lithiation and during delithiation, Reprinted with permission from 76, Copyright 2011, Elsevier. b. Mechanism of the process of the self-healing $\mathrm{CuGa}^{2}$ electrode, Reprinted with permission from 78, Copyright 2019, Elsevier.

For the first time, Han et al. reported consisting of a gallium-indium-tin (GaInSn) alloy $\mathrm{Si}$ composite anode by Ga particles break during cycling covers cracks (Fig. 17). [77]. This type electrode exhibit TO electrochemical performance of $630 \mathrm{mAh} / \mathrm{g}$ capacitance at $200 \mathrm{mAhg}-1$ (Fig. 18) [78]. Cyclic voltammetry (CV) curves of Nyquist plots show perfect cycling performance of lithium batteries for self-healing composite electrode. [77]. 


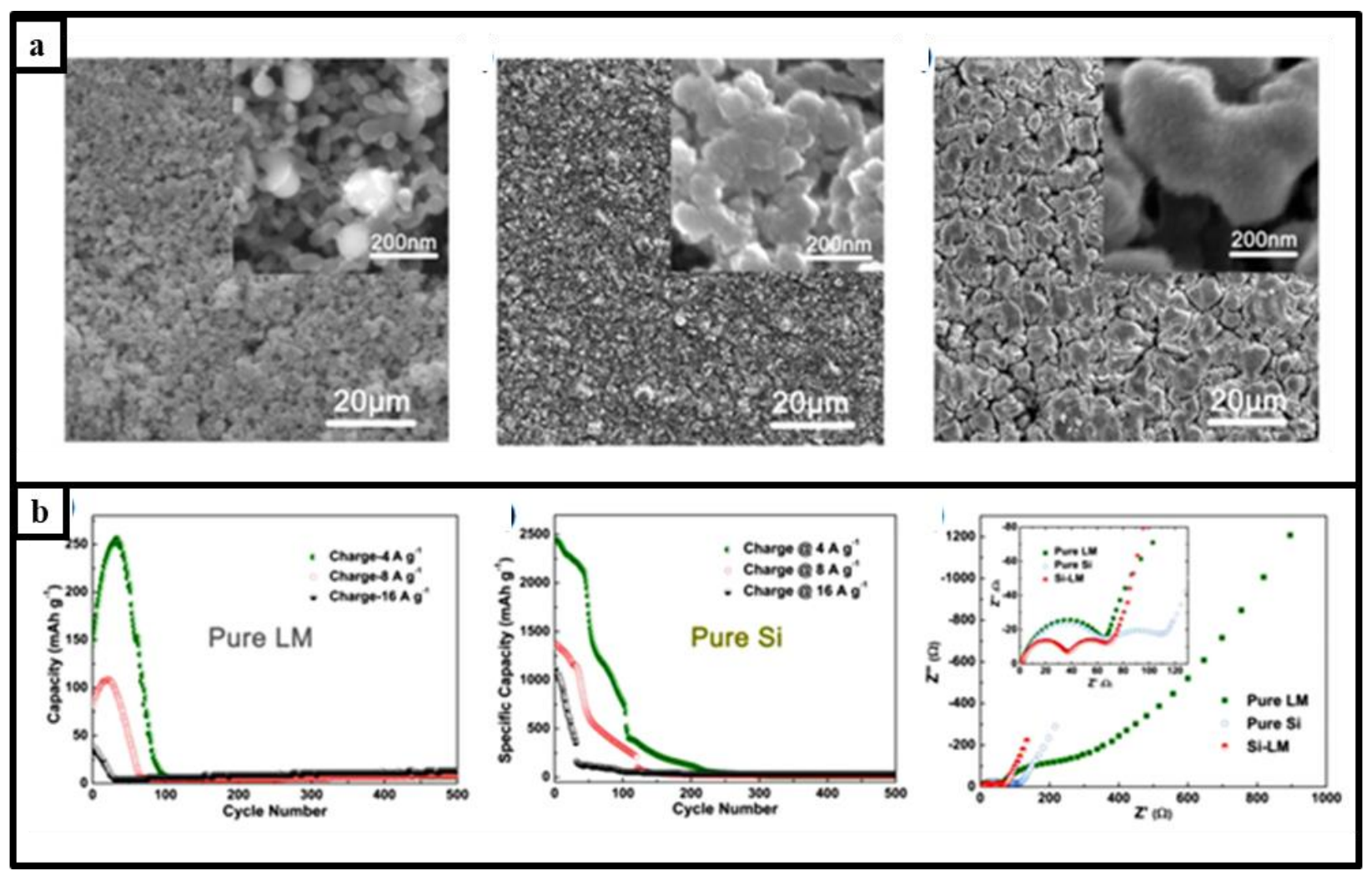

Figure 6. a. Morphology of Liquid metal/Silicon electrode before cycle, after 200th cycle and after 1500th cycle. b. Capasity-Cycle graph of Liguid metal anode and Si anode cycled using different current density for 500 cycles; Nyquist graph of Liguid metal anode, Liguid metal/Silicon anode and Silicon anode Reprinted with permission from 77, Copyright 2018, Elsevier.

$\mathrm{Fe}^{3+}$ and (tris)catechol is like a crosslinked polymeric network (Figure 7c) that gives flexibility. A tridentate ligand structure Fe3+ and (tris)catechol gained flexibility. [79] Metals not only benefit from their low melting point temperature, but also contribute to displaying reversible properties by coordinating with polymeric networks. It helps maintain electrical and mechanical integrity and significantly suppresses the volume expansion of the Silicon anode by forming coordination bonds with the $\mathrm{Ca}^{2+}$ cations of the alginate chainsself-healing mechanism with hydrogen bonds. As a result, this structure shows capacity of $2522 \mathrm{mAh} / \mathrm{g}$ with $76.5 \%$ capacity retention after 500 cycle [80]. Metals are used to coordinate more alginate chains with the alginate, which is expected to crosslink. The results show that Si anodes with Al-algae or Ba-algae binding are more robust and represent higher capacity retention with their reversible properties. Yoon et al has developed a simple Ca-spray treatment method $\mathrm{Ca}^{2+}$ doped alginate $\mathrm{Si}$ anode composite prepared with the mechanical properties of cross-linked alginate are greater hardness, toughness and flexibility than 
Na-alginate, CMC and PVDF binders. LIBs are anticipated to have a longer life and higher charge capacity than others. The Si-Ca electrodes have $1711 \mathrm{~mA} \mathrm{~h} \mathrm{g1} \mathrm{charge} \mathrm{capacity} \mathrm{at} 0.2 \mathrm{~A} \mathrm{~g} 1$, and even at high current density $2000 \mathrm{~mA} / \mathrm{g}$ [81]. It has been shown that it gains self-healing properties with the coordination of $\mathrm{Fe} 3+$ (tris)catechol. An anode in this coordination structure exhibits $81.9 \%$ capacity retention after 350 cycles at $1 \mathrm{C}$. [79].

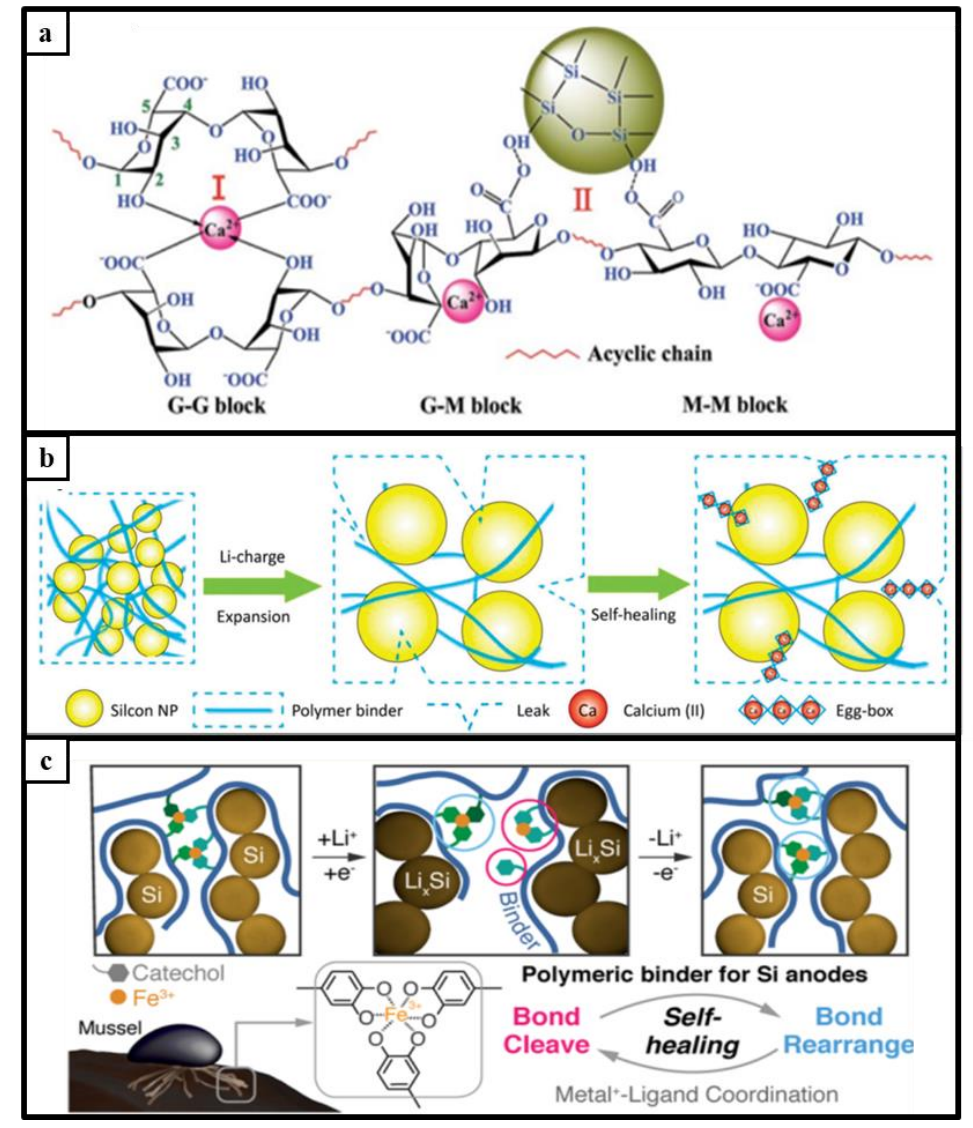

Figure 7. a. Schema of coordinate bonds between alginate chains and calcium cations, Reprinted with permission from 80, Copyright 2014, Elsevier. b. Self-healing mechanism of Caalginate/Silicon anode during cycling, Reprinted with permission from 81, Copyright 2014, Elsevier. c. Schema of Silicon/Self-healing binder, Reprinted with permission from 79, Copyright 2019, Advanced Materials 
Table 2. Some self-healing electrodes for self-healing mechanism on metal interaction

\begin{tabular}{|c|c|c|c|c|}
\hline Self-healing Properties via & $\begin{array}{l}\text { Anode Active } \\
\text { Material }\end{array}$ & Electrolyte & $\begin{array}{l}\text { Electrochemical } \\
\text { performance }\end{array}$ & Ref. \\
\hline $\begin{array}{l}\text { Solid-liquid transition of } \\
\text { Gallium }\end{array}$ & Liquid Gallium & $1 \mathrm{M} \mathrm{LiPF}_{6} \mathrm{EC} / \mathrm{DEC} / \mathrm{DMC}$ & $\begin{array}{l}626 \mathrm{mAh} / \mathrm{g} \\
\text { at } \mathrm{C} / 5\end{array}$ & {$[76]$} \\
\hline Alginate binder with $\mathrm{Ca}^{2+}$ ions & $\begin{array}{l}\text { Silicon sub- } \\
\text { microparticule } \\
\text { 200nm }\end{array}$ & $\begin{array}{l}1 \mathrm{M} \mathrm{LiPF} 6 \mathrm{EC} / \mathrm{DEC} / \mathrm{DMC} \\
\text { (1:1:1 volume ratio) }\end{array}$ & $\begin{array}{l}2522 \mathrm{mAh} / \mathrm{g} \text { after } 500 \text { cycles } \\
20 \mathrm{C}\end{array}$ & {$[80]$} \\
\hline $\mathrm{Ca}$-alginate binder & Silicon & $\begin{array}{l}1.3 \mathrm{M} \mathrm{LiPF}_{6} \mathrm{EC} \mathrm{EMC}, 3: 7 \\
10 \mathrm{wt} \% \mathrm{FEC}\end{array}$ & $\begin{array}{l}1711 \mathrm{~mA} \mathrm{~h} \mathrm{~g} 1 \text { charge } \\
\text { capacity at } 0.2 \mathrm{~A} / \mathrm{g} 2000 \\
\mathrm{~mA} / \mathrm{g}\end{array}$ & {$[81]$} \\
\hline Low melting temperature & Ga-In-Sn alloy & $\begin{array}{l}1 \mathrm{M} \mathrm{LiPF}_{6} \text { in } \\
\mathrm{EC} / \mathrm{EMC}^{\mathrm{DMMC}}\end{array}$ & $2300 \mathrm{mAh} / \mathrm{g}$ at $0.25 \mathrm{C}$ & [77] \\
\hline $\begin{array}{l}\text { Fe- } \beta \text {-catechol } \\
\text { coordination } \\
\text { bonds }\end{array}$ & $\begin{array}{l}\text { Silicon } \\
\text { microparticule }\end{array}$ & $\begin{array}{l}1 \mathrm{M} \mathrm{LiPF}_{6} \text { in } \\
\mathrm{DMC} / \mathrm{EC}\end{array}$ & $81.9 \%$ after 350 cycles at $1 \mathrm{C}$ & [79] \\
\hline $\begin{array}{l}\text { The lithiation-delithiation } \\
\text { mechanism }\end{array}$ & $\begin{array}{l}\text { Liquid } \mathrm{CuGa}_{2} / \mathrm{Si} \\
\text { nanocomposite }\end{array}$ & $1 \mathrm{M} \mathrm{LiPF}_{6}$ in $\mathrm{EC} / \mathrm{DEC}$ & $630 \mathrm{mAh} / \mathrm{g}$ at $200 \mathrm{~mA} / \mathrm{g}$ & {$[78]$} \\
\hline
\end{tabular}

\subsubsection{Host-guest Interactions}

Kwon et al. fabricated the host-guest interactions with hyperbranched $\beta$-cyclodextrin polymer (Figure 8), and dendritic gallic acid crosslinker with six adamantane units by host part. crosslinking polymer binders are provided with interaction between the guest and host polymer chains provide for silicon surface cracks, resulting in approximately $90 \%$ capacity retention at 150 cycles [82]. 


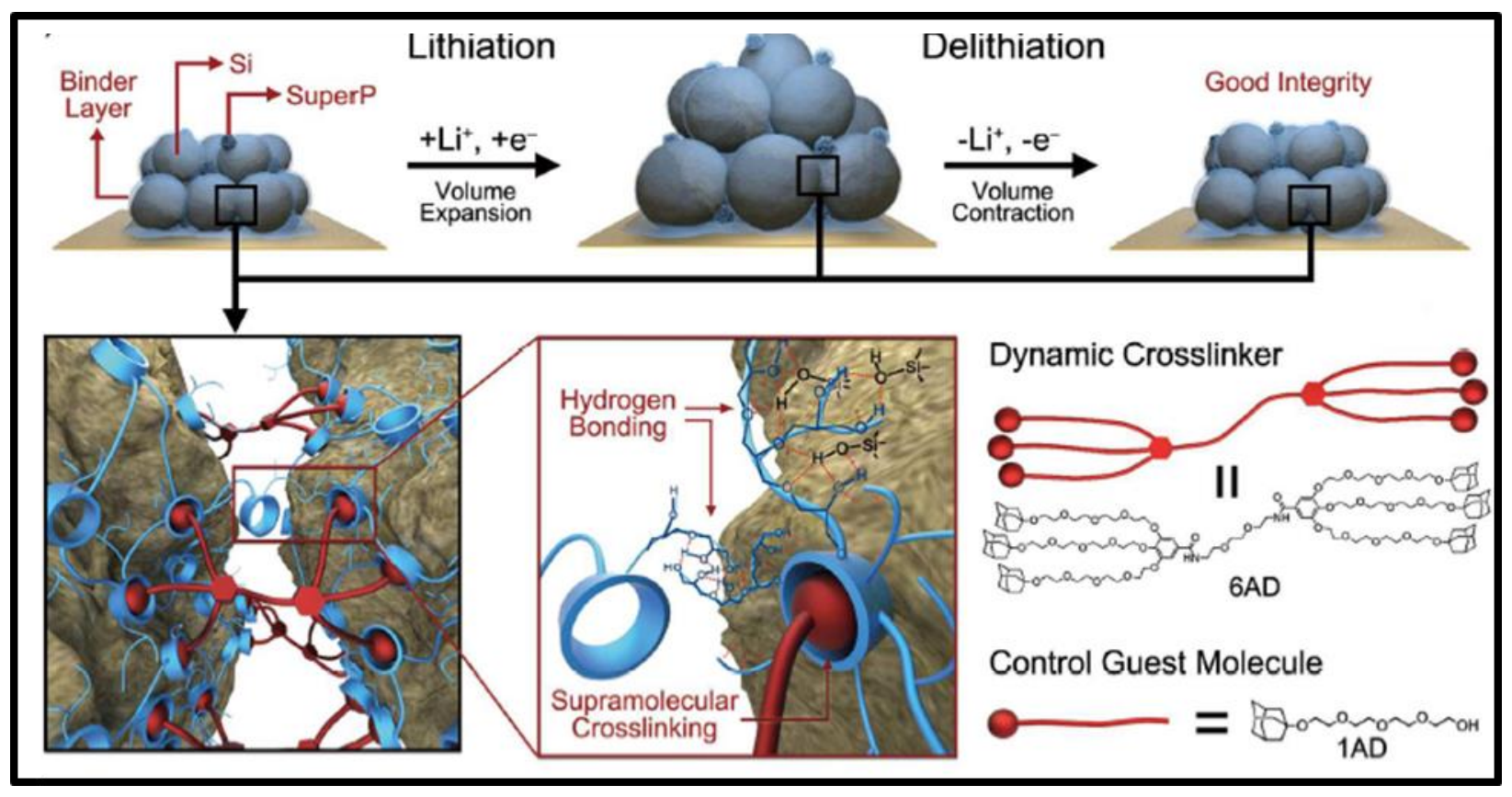

Figure 8. The mechanism of dynamic crosslinking chemical structures of guest molecules for Silicon anode, Reprinted with permission from 82, Copyright 2015, American Chemical Society

Table 3. Some self-healing materials for host-guest interactions self-healing mechanism

\begin{tabular}{|l|l|l|l|l|}
\hline Self-healing material & $\begin{array}{l}\text { Anode Active } \\
\text { materials }\end{array}$ & Electrolyte & Electrochemical performance & Ref. \\
\hline $\begin{array}{l}\text { Crosslinked Hyperbrancher } \beta- \\
\text { cyclodextrin and gallic acid }\end{array}$ & Silicon & $\begin{array}{l}1 \mathrm{M} \mathrm{LiPF}_{6} \text { in } \\
\mathrm{EC} / \mathrm{DEC} / \mathrm{VC} / \mathrm{FEC}\end{array}$ & $\begin{array}{l}1500 \mathrm{mAh} / \mathrm{g} \text { at } 0.5 \mathrm{C} ; 90 \% \\
\text { retained after } 150 \mathrm{cycles}\end{array}$ & {$[82]$} \\
\hline
\end{tabular}

\subsubsection{Ionically Bonded Interaction}

Polymeric materials with macromolecules consisting of ionic and/or ionizable groups can be developed that show the advantage of reversible physical cross-links for self-healing function, forming interactions not found in non-ionic polymers. The ionic content can assist the diffusion/sealing process and stabilize the fracture resistance of the polymer material. For the first time, binders that gained self-healing properties with meldrum acid for silicon anodes were reported by Kwon and coworkers. For this, Lithium 2-methyl-2-(4-vinyl benzyl) malonat is synthesized with hydrolysis of units of Meldrum's acid (Figure 9a) upon Lithium dicarboxylate using ion-dipole interactions. The cycling performance of polymer composite and silicon is $51 \%$ capacity retention at 500 cycles [83]. Wu et al created a self-healing porous scaffold structure by exploiting the electrostatic interaction between the carboxylate $\left(-\mathrm{COO}^{-}\right)$of $\mathrm{Alg}$ and the protonated 
amines $\left(-\mathrm{NH}^{+}\right)$of $\mathrm{C}$-chitosan in the alginate-carboxymethyl chitosan (Alg-C-chitosan) composite polymer (Figure 9d). Si-based anode using Alg-C-chitosan composite binder exhibited excellent cycle stability with a residual capacity of $750 \mathrm{mAh} / \mathrm{g}$ after the $100^{\text {th }}$ cycle [20].

The Polymer binder found by Zeng et al shows lithium-ion dispersion and electron conductivity 14 and 90 times higher, respectively, than the commonly used carboxymethyl cellulose and acetylene black. Prepared from this ionic (polyethylene oxide and polyethylenimine) polymer binder, the silicon anode has a high capacity of approximately $2000 \mathrm{~mA} \mathrm{hg}-1$ at 500 cycles at $1 \mathrm{C}$ [73]. Huang et al. developed self-healing ionomer-electrode that presents an better initial discharge areal capacity of $2.9964 \mathrm{mAh} \mathrm{cm}^{-2}$ compared with $2.9748 \mathrm{mAh} \mathrm{cm}^{-2}, 2.895 \mathrm{mAh} \mathrm{cm}^{-2}, 2.991 \mathrm{mAh}$ $\mathrm{cm}^{-2}$ at a rate of $0.1 \mathrm{C}$ for electrodes with PVDF, SBR and uncrosslinked ionomer binder, respectively. Coulombic efficiency of electrodes that use SBR and PVDF is lower than coulombic efficiency of self-healing systems [11].

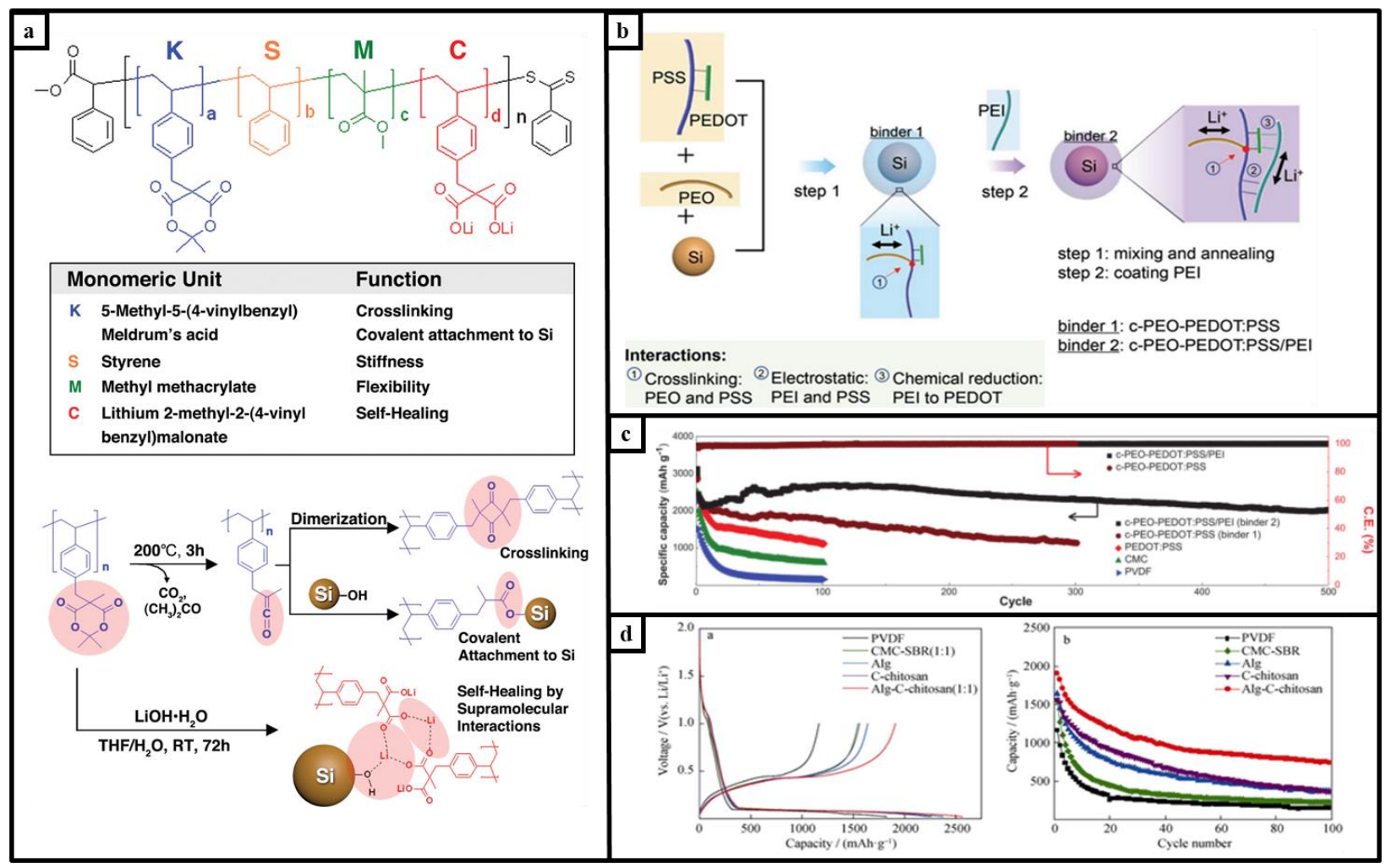

Figure 9. a. Chemical structures of polymers (top) and synthesis of lithium 2-methyl-2-(4vinylbenzyl) malonate from Meldrum's acid, Reprinted with permission from 83, Copyright 2014, Advanced Materials. b. Schema of the interactions Silicon particles with self-healing PEOPEDOT:PSS and PEO-PEDOT:PSS/PEI binders, Reprinted with permission from 84, Copyright 2018, Advanced Materials. c. Capacity-Cycle graphs of Silicon electrodes with PVDF, CMC, 
PEDOT:PSS and derivatives as a binders, Reprinted with permission from 11, Copyright 2018, Royal Society of Chemistry. d. Capacity-Voltage and Capacity-Cycle graphs of Silicon electrode with PVDF, CMC-SBR, Alginate Alginate-C-chitosan binders, Reprinted with permission from 20, Copyright 2019, Advanced Materials

Table 4. Some self-healing materials for ionically bonded interactions self-healing mechanism

\begin{tabular}{|l|l|l|l|l|}
\hline $\begin{array}{l}\text { Self-healing } \\
\text { material }\end{array}$ & $\begin{array}{l}\text { Anode Active } \\
\text { materials }\end{array}$ & Electrolyte & Electrochemical performance & Ref. \\
\hline Meldrum's acid & Silicon & $1 \mathrm{M} \mathrm{LiPF}_{6}$ in EC/DEC & $\begin{array}{l}1743 \mathrm{mAhg}-1 \text { at } 2000 \mathrm{~mA} / \mathrm{g} ; 74 \% \\
\text { retained after } 200 \text { cycles }\end{array}$ & {$[83]$} \\
\hline Alg-C-chitosan & Silicon & $1 \mathrm{M} \mathrm{LiPF}_{6}$ in EC/DEC & $750 \mathrm{mAh} / \mathrm{g}$ after the 100th cycle & {$[20]$} \\
\hline $\begin{array}{l}\text { Ionic polymer with } \\
\text { PEDOT:PSS, PEO, } \\
\text { and PEI }\end{array}$ & Silicon & $\begin{array}{l}1 \mathrm{M} \mathrm{LiPF}_{6} \mathrm{EC} / \mathrm{DEC} \\
(1: 1 \text { volume ratio } \\
\text { with } 5 \% \mathrm{FEC}\end{array}$ & $\begin{array}{l}\text { over } 2000 \mathrm{mAh} / \mathrm{g} \text { after } 500 \text { cycles at } \\
1.0 \mathrm{~A} / \mathrm{g}\end{array}$ & {$[84]$} \\
\hline $\begin{array}{l}\text { Content of binder/ } \\
\text { conductive additive } \\
(\%) 1.8 / 8\end{array}$ & Si/graphite & $\begin{array}{l}1 \mathrm{M} \mathrm{LiPF} 6 \\
\text { EC/DEC/EMC } \\
(2: 3: 1 \text { volume ratio })\end{array}$ & $3 / 0.5 \mathrm{C} 71.7 \%$ @ $100 \mathrm{cycles}$ & {$[11]$} \\
& & & & \\
\hline
\end{tabular}

\subsubsection{Multiple Functional Interaction Self-healing Mechanism}

Self-healing properties can be intra-molecular and intermolecular, as well as a self-healing material with physical interaction combined with chain movements and multi-level chemical interactions obtained by repairing more than one type of chemical entity in a single material. Lim et al. reported PAA-PBI binding using supremolecular interaction with ionic bond and hydrogen bond. This highlights that the structure using only PAA binder with 0.45 peeling and the structure using $2 \%$ by weight PBI relative to PAA show close mechanical properties. Thus, it shows that a tight conducting network (Figure 10a) is obtained using PAA-PBI-2. This mechanical property is related to the proportional reversibility of hydrogen bonding and ionic interactions. The electrode with the PAA-PBI-2 connector showed a high initial capacity of $1376.7 \mathrm{mAh} / \mathrm{g}$ and improved capacity retention of $54.6 \%$ after 100 cycles, which was much better than the other two connectors. The bond strength of the bonding network with Si will decrease with increasing PBI ratio because the ionic interaction between PBI and PAA provides a lower amount of carboxylic acid to adhere to the Si surface [85]. The cycle performance of the electrodes can be improved with two or more different types of dynamic bonds in a well-designed binder. Kim et al. reported a polymer linker 
composed of DNA (reDNA) and NaAlg using two supramolecular interactions. This supramolecular interaction (Figure 10c) suppresses the volume change of the Si electrode by physically crosslinking the hydrogen bond and the ionic bond. The Si/reDNA/NaAlg electrode exhibited a capacitance efficiency of $80.1 \%$ after 160 cycles at a current density of $1.75 \mathrm{Ag} 1$, while the blank trials $\mathrm{Si} / \mathrm{reDNA}, \mathrm{Si} / \mathrm{DNA}$ and $\mathrm{Si} / \mathrm{NaAlg}$ electrodes achieved an effeciency of $67.8 \%$, $61.3 \%$ and $48.6 \%$, respectively [86]. Xu et al. showed that a polymer that has multiple interactions of poly(acrylic acid)-poly(2-hydroxyethyl acrylate-co-dopamine methacrylate) (Figure 10b) prepared by mixing PAA with P(HEAco-DMA). An extremely stable cycle life was demonstrated with the PAA-connected electrode alone showed a much faster capacitance drop over 100 cycles than this combined polymer [15].

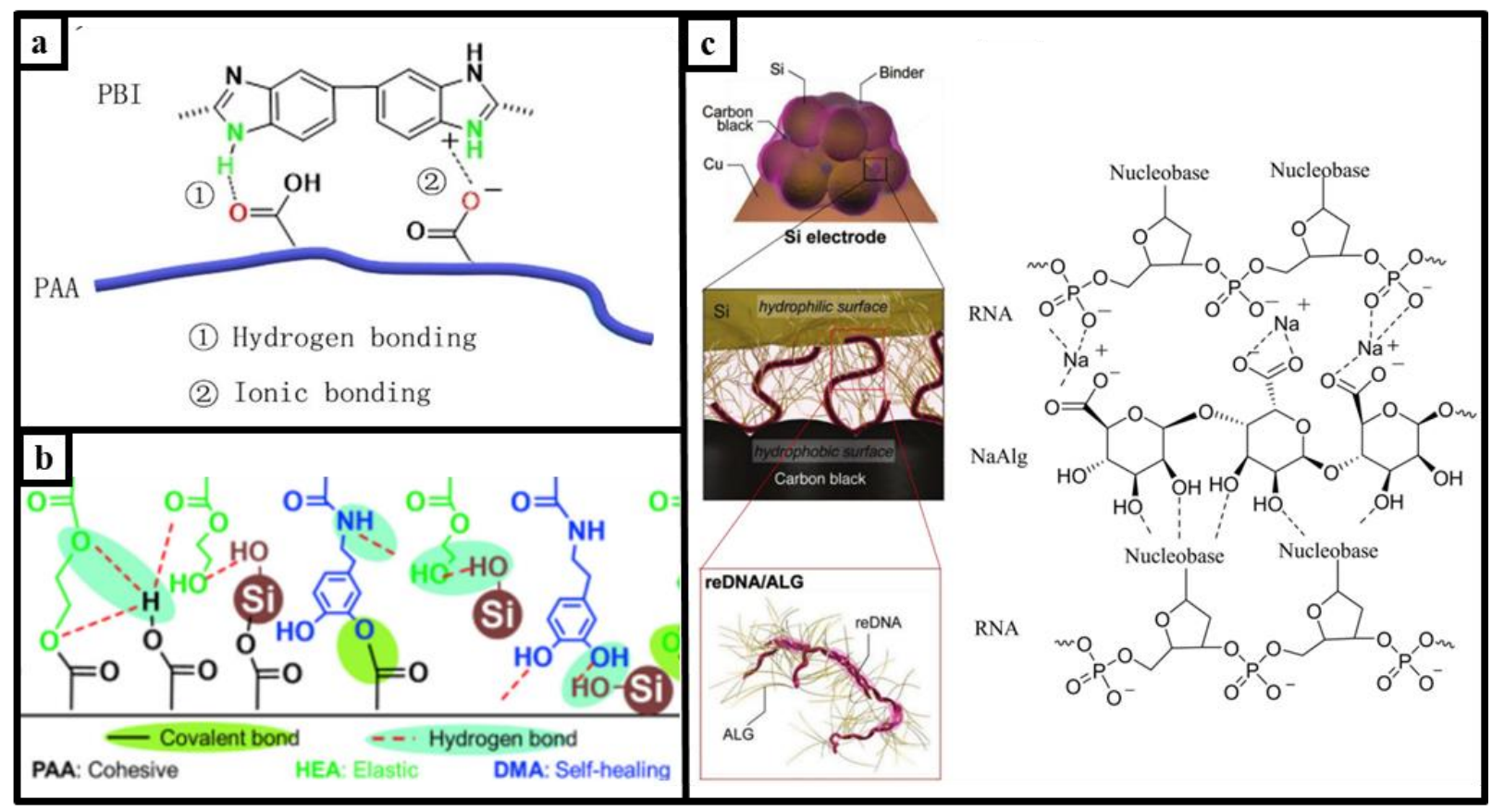

Figure 10. a. The chemical structure of PAA-PBI, Reprinted with permission from 85, Copyright 2015, American Chemical Society. b. Self-healing interaction with Silicon and binder, Reprinted with permission from 15, Copyright 2018, Elsevier. c. The interactions between binder, Silicon particles and CB (right) and the structure of reDNA/Alginate (left), Reprinted with permission from 86, Copyright 2018, Advanced Materials 
Table 5. Some self-healing materials for multiple functional interaction self-healing mechanism

\begin{tabular}{|l|l|l|l|l|}
\hline Self-healing material & $\begin{array}{l}\text { Anode Active } \\
\text { materials }\end{array}$ & Electrolyte & Electrochemical performance & Ref. \\
\hline $\begin{array}{l}\text { PAA-PBI with } \\
\text { H bond- Ionic bond }\end{array}$ & Silicon & $\begin{array}{l}1 \mathrm{M} \mathrm{LiPF}_{6} \text { in } \\
\mathrm{EC} / \mathrm{DEC}\end{array}$ & $\begin{array}{l}1376.7 \mathrm{mAh} / \mathrm{g} \text { and improved capacity } \\
\text { retention of } 54.6 \% \text { after } 100 \text { cycles, }\end{array}$ & {$[85]$} \\
\hline $\begin{array}{l}\text { reDNA/NaAlg } \\
\text { Hydrophobic interaction }\end{array}$ & Silicon & $\begin{array}{l}1 \mathrm{M} \mathrm{LiPF}_{6} \text { in } \\
\text { EC/DEC }\end{array}$ & $80.1 \%$ after 160 cycles at $1.75 \mathrm{~A} / \mathrm{g}$ & {$[86]$} \\
\hline $\begin{array}{l}\text { PAA-P(HEAco-DMA) } \\
\text { H bond- Covalent bond }\end{array}$ & Silicon & $\begin{array}{l}1 \mathrm{M} \mathrm{LiPF}_{6} \\
\text { EC/DEC }\end{array}$ & $\begin{array}{l}1,855 \mathrm{mAh} / \mathrm{g} \text { at } 5 \mathrm{~A} / \mathrm{g} \text { under } \mathrm{Si} \\
\text { loading of } 1 \mathrm{mg} / \mathrm{cm}^{2}\end{array}$ & {$[15]$} \\
\hline
\end{tabular}

\subsection{Chemical Interaction based Self-Healing Materials}

Reversibility of covalent bonds can use condensation, exchange, and addition reactions. For the first time, Kim et al developed self-healing processed by a thermoplastic polyurethane (TPU) designed by easy-to-process aromatic disulfides can properly self-heal within 2 hours by aromatic disulfide metathesis [88]. Xu et al. He was inspired by nature to prepare a new poly(urea-urethane)graphite carbon nitride nanolayer composite material in which multiple hydrogen bonds in the PUU matrix imparts graphitic carbon nitride with self-healing ability at room temperature to the composite material. Improved mechanical properties to the composite material are provided by nanolayers that serve as both chemical and physical crosslinkers [88]. Li and coworkers reported a supramolecular polymer type using a host-guest complex of visible light-labile picolinium $\beta$ cyclodextrin nanogels $(\beta-C D)$ ultrastability against electrolytes, and photodegradation properties [27]. Most self-healing artificial materials are polymer-based [17]. Self-healing mechanisms can be classified in various ways according to the way of breaking and joining of bonds, intramolecular and intermolecular interactions, external excitations and polymer network structures. In its simplest form can be considered two main types as covalent and non-covalent. self-healing mechanisms with dynamic non-covalent bonds are hydrogen bonding, ionic interactions, metal coordination, $\pi-\pi$ stacking or hydrophobic interactions, while self-healing mechanisms with dynamic covalent bonds include diels-alder reaction, disulfide, acylhydrazone, ester, imine. The Diels-Alder (DA) reaction for crosslinking linear polymers has been pioneered by Kennedy and Wagener over the last four decades $[89,90]$. The crosslinkable and reversible groups of the thermoreversible polymers were attached to linear polymer backbones, but the links of crosslinkers to polymer backbones were not reversible, using a completely reversible crosslinking covalently 
formed macromolecular macromolecular network reported by Chen et al [91]. A mechanically self-healing electrode was successfully developed by Lee et al by placing Ag nanowires and polydimethylsiloxane-based polyurethane (PDMS-CPU) crosslinked with Diels-Alder (DA) adducts. A combination of DA reaction coated AgNWs on the surface of the polymer, smoothing the polymer surface, greatly improving the surface mechanical sustanability of the electrode [92]. As a resemblance to this work, a transparent electrode, a thermally replaceable electrode was developed by Pyo et al, again containing polyurethane Ag nanowires as crosslinkers [93].

As an alternative to the self-healing chemistry of covalently bonded rubber materials, the Disulfide mechanism is used [94]. Firstly, Tobolsky et al. showed change of sulfur-sulfur bonds in poly(ethylene disulfide) and poly(ethylene tetrasulfide), as well as polyurethanes [95] [96]. Disulfide groups can be cleaved by a reduction reaction to form two thiol groups. Then it can be regenerated by oxidation. Tesoro et al. developed a re-formed in epoxy resins with disülfide interaction [97, 98]. Finally, synthesized thiol-terminated poly(styrene) via disülfide interaction during reduction-oxidation was reported by Tsarevsky et al [99]. Kuhl et al. studied self-healing polymer networks obtained by polymerization of an acylhydrazone crosslinker and methacrylates to improve the mechanical properties of the polymer by adjusting the $\mathrm{Tg}$ [100]. Uncrosslinked polymers and those with reversible crosslinks can be processed but are soluble. Leibler and colleagues demonstrated the reprocessability of epoxy acid network polymers at high temperatures with ester bonds in a covalent network. [101]. Yu et al showed thermally malleable polymers which undergo covalent bond esterification exchange reactions that the glass transition temperature of the material increases as the proportion of hard segments in the epoxy increases [102]. Imine chemistry, also known as Schiff base chemistry, is reversible covalent interaction [103]. Chao et al., with organic solvents of varying polarity of poly(ethylene glycol) bis(3aminopropyl) to 1,3,5-triformylbenzene, where imine bond exchange is induced by residual primary amino functionalities in the polymeric network. [104]. 


\subsubsection{Imine bond based self-healing systems}

According to Cao et al. Catechol-functionalized chitosan cross-linked with glutaraldehyde (CSCG+GA) (Figure 11a), a SiNP-based anode with polymer mesh (CS-CG 10\%+6\%GA) via catechol grafting, 91.5\% after 100 cycles, $2144 \pm 14 \mathrm{mAh} / \mathrm{g}$ showed a capacity retention. [105]. Rajevv et al. self-healing network formed between amino groups in glycol chitosan and aldehyde groups (Figure 11b). These components include dynamic Schiff some reactions. Si electrodes (GCS-I-OSA) exhibits a high degree of reversibility of $2316 \mathrm{mAh} / \mathrm{g}$ at $0.2 \mathrm{C}$ after 100 cycles, while $\mathrm{Si} /$ graphite composite anodes at a current density of $0.2 \mathrm{C}$ after 100 cycles. It exhibited a specific capacity of $1364 \mathrm{mAh} / \mathrm{g}$ [106].

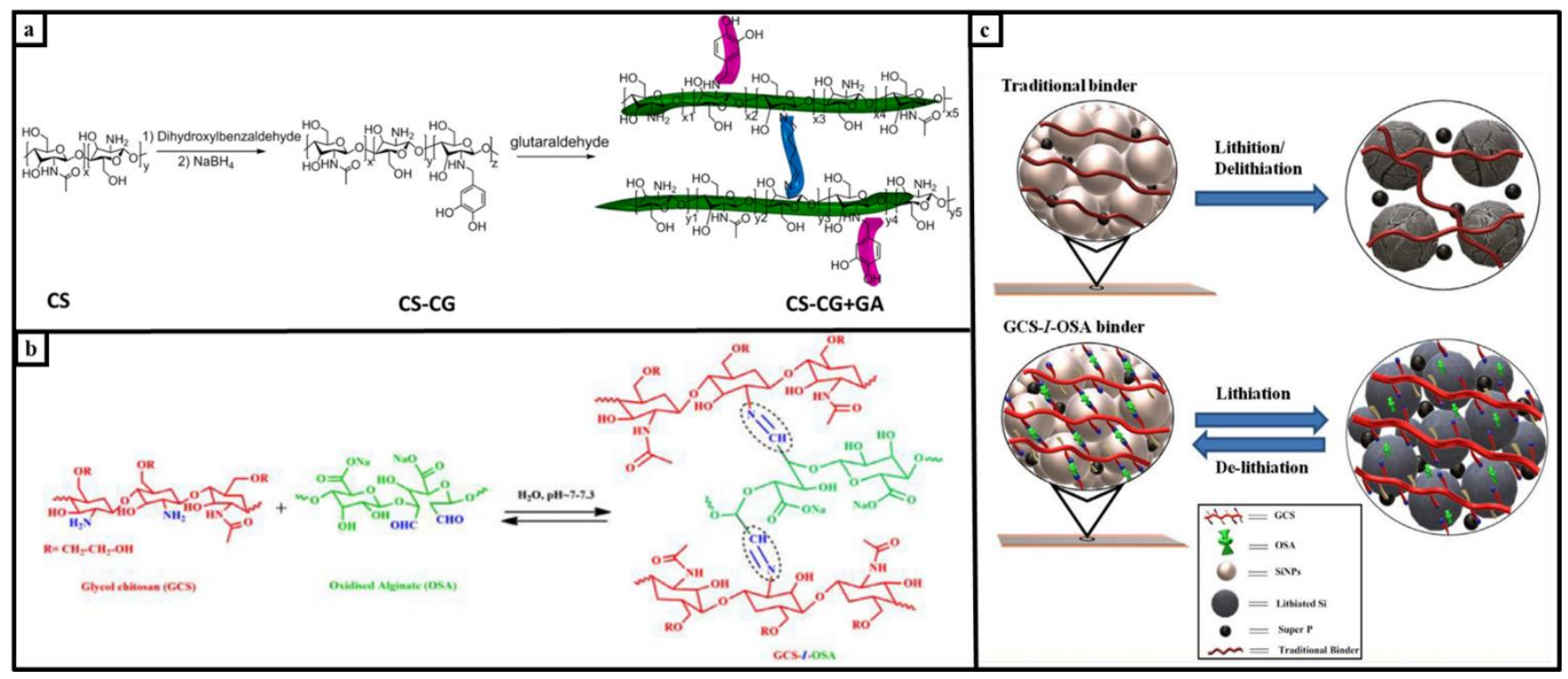

Figure 11. Synthesis of a Crosslinking Catechol-Rich CS Network, Reprinted with permission from 105, Copyright 2019, American Chemical Society. b. The self-healing process between glycol chitosan and oxidized alginate (OSA) (right) and schematic comparison of GCS-I-OSA binder and traditional binder, Reprinted with permission from 106, Copyright 2020, Elsevier. 
Table 6. Some self-healing materials for imine bonded interactions self-healing mechanism

\begin{tabular}{|l|l|l|l|l|}
\hline Self-healing material & $\begin{array}{l}\text { Anode Active } \\
\text { materials }\end{array}$ & Electrolyte & Electrochemical performance & Ref. \\
\hline $\begin{array}{l}\text { Catechol-functionalized } \\
\text { chitosan cross-linked by } \\
\text { glutaraldehyde }\end{array}$ & $\begin{array}{l}\text { Silicon } \\
\text { nanoparticule }\end{array}$ & $1 \mathrm{M} \mathrm{LiPF}_{6}$ in EC/EMC & $\begin{array}{l}91.5 \% \text { after } 100 \text { cycles } 2144 \pm \\
14 \mathrm{mAh} / \mathrm{g} .\end{array}$ & {$[105]$} \\
\hline GCS-I-OSA & $\begin{array}{l}\text { Silicon powder } \\
50 \mathrm{~nm}\end{array}$ & $1 \mathrm{M} \mathrm{LiPF}_{6}$ in EC/DEC & $\begin{array}{l}1364 \mathrm{mAh} / \mathrm{g} \text { at } 0.2 \mathrm{C} \text { after } 100 \\
\text { cycles }\end{array}$ & {$[106]$} \\
\hline
\end{tabular}

\subsubsection{Ester bond based self-healing systems}

Ryu et al investigated the natural guar gum component BC-g on Si anode. This binder, which will maintain the electrode integrity over long cycles, adheres strongly to the surface of the Si particles with its hydroxyl content. In the polymer, the bonding between the boronic acid side groups on the polystyrene backbone and the hydroxyl groups on the guar gum increases the mechanical strength. Hydroxy H-bonds and borate ester bonds form the self-healing mechanism. By putting a drop of electrolyte solvent on the broken surfaces, the polymer was able to reconnect the new surfaces. The prepared Si electrode containing the developed polymer binders retained $70 \%$ capacity after 300 cycles at $1 \mathrm{C}[106]$.

Jung et al improved that $\mathrm{Si}$ anode, that have properties stabilizing the SEI layer, and preventing the volumetric expansion of Si aggregation with used binder (Figure 12), produced with polymeric binder via covalent bond formation between $-\mathrm{OH}$ groups on produced Si's surface and an esterification with polyacrylic acid. This combination exhibited a capacity of $1500 \mathrm{~mA} \mathrm{~h} \mathrm{~g} \mathrm{~g}^{-1}$ after 500 cycles at $1000 \mathrm{~mA} \mathrm{~g}^{-1}[107]$. 


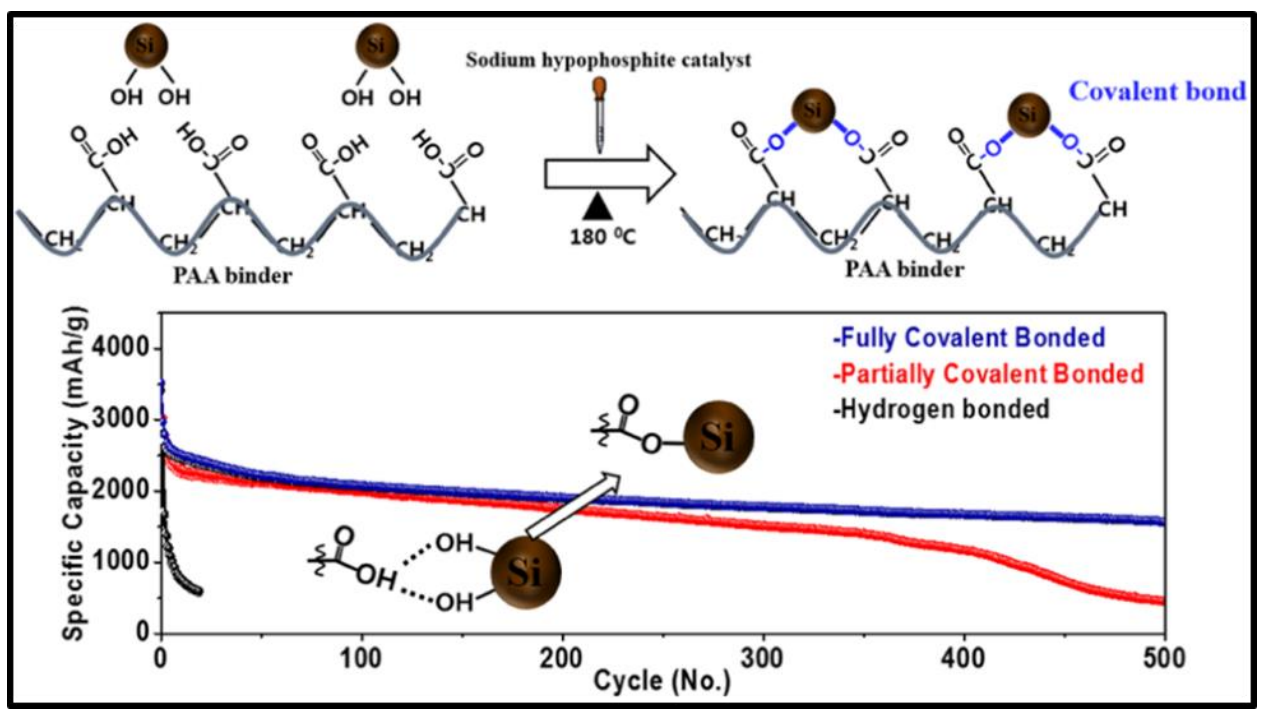

Figure 12. Cycle-Capacity of the different types Silicon electrodes and the interactions between Si nanoparticles and PAA binder, Reprinted with permission from 107, Copyright 2019, American Chemical Society

Table 7. Some self-healing materials for boronate ester bond self-healing mechanism

\begin{tabular}{|c|c|c|c|c|}
\hline Self-healing material & $\begin{array}{l}\text { Anode Active } \\
\text { materials }\end{array}$ & Electrolyte & Electrochemical performance & Ref. \\
\hline BC-g & $\begin{array}{l}\text { Silicon powder } \\
50 \mathrm{~nm}\end{array}$ & $\begin{array}{l}1.3 \mathrm{M} \mathrm{LiPF}_{6} \text { in } \\
\text { DEC/EC }\end{array}$ & $\begin{array}{l}2750 \mathrm{mAh} / \mathrm{g} \text { at } 0.2 \mathrm{C} 87.3 \% \text { after } \\
100 \text { cycles }\end{array}$ & [106] \\
\hline Esterificated PAA & $\begin{array}{l}\text { Silicon powder } \\
50 \mathrm{~nm}\end{array}$ & $\begin{array}{l}1 \mathrm{M} \mathrm{LiPF} 6 \text { in } \mathrm{DEC} / \mathrm{EC} / \mathrm{DMC} \\
1: 1: 110 \% \mathrm{FEC}\end{array}$ & $\begin{array}{l}1500 \mathrm{mAh} / \mathrm{g} \text { after } 500 \text { cycles at } \\
1000 \mathrm{mAh} / \mathrm{g}\end{array}$ & [107] \\
\hline
\end{tabular}

\subsubsection{Disulfide bond based self-healing systems}

It affects the molecular behavior of the types and steric hindrance of self-healing fragments between different polymer chains and can self-heal and mechanical properties. The urea groups are self-healing by differences between the thiourea and urea hydrogen bond moieties.

A double-wrapped binder polyacrylic acid (PAA) and binder using outer polyurethane (BFPU) polymers (Figure 13) to address the large internal stress of low Young's modulus bifunctional silicone was developed by Jiao. BFPU acts as a buffer layer to disperse the internal tension and stress during lithiation. This prevents structural damage to the hard PAA. Thus, large volume changes are prevented during the charge-discharge process. Si anodes that developed with PAABFPU binder have capacity of $3.5 \mathrm{mAh} \mathrm{cm}^{-1}$ and over $88 \%$ capacity retention for 200 cycles [108]. 


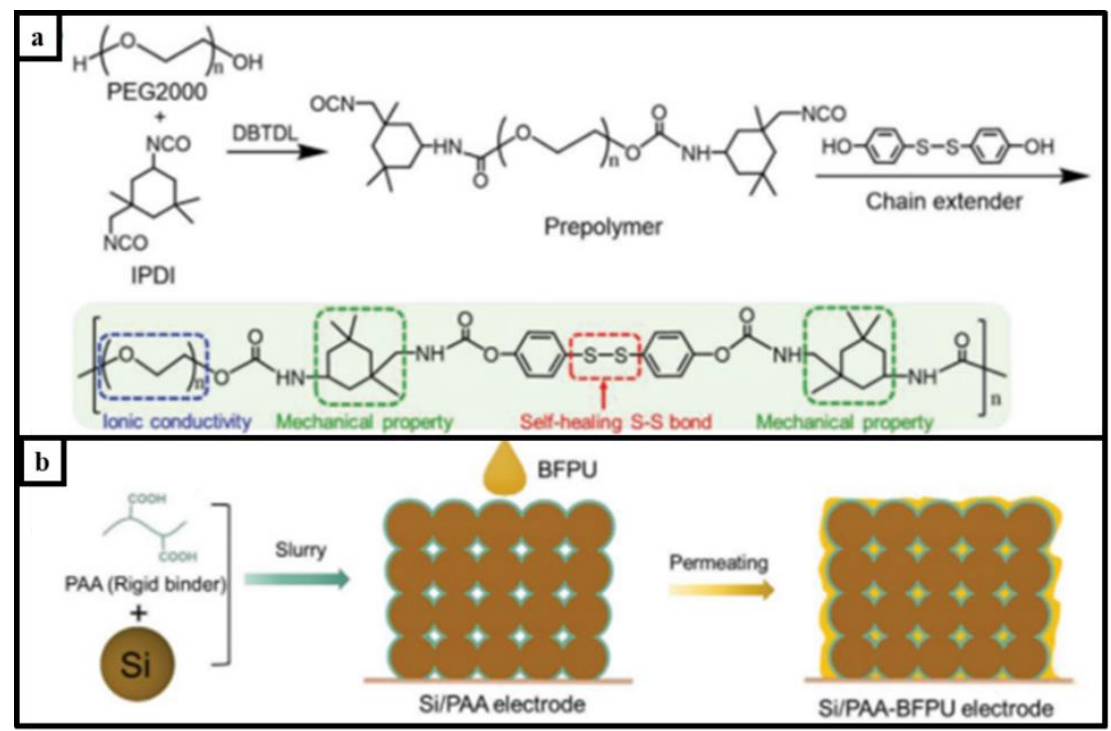

Figure 13. a. The BFPU polymer. b. Silicon electrode with PAA-BFPU binder, Reprinted with permission from 108, Copyright 2021, Advanced Materials

Table 8. Some self-healing materials for disulfide bonded interactions self-healing mechanism

\begin{tabular}{|l|l|l|l|l|}
\hline Self-healing material & $\begin{array}{l}\text { Anode Active } \\
\text { materials }\end{array}$ & Electrolyte & Electrochemical performance & Ref. \\
\hline Poly(ether- thioureas) & Silicon powder & $\begin{array}{l}1 \mathrm{M} \mathrm{LiPF}_{6} \text { in } \\
\mathrm{DEC/EC/DMC}\end{array}$ & $1325 \mathrm{mAh} / \mathrm{g}$ at $1 \mathrm{C}$ & {$[109]$} \\
\hline PAA-BFPU binder & $\begin{array}{l}\text { Silicon powder } \\
100 \mathrm{~nm}\end{array}$ & $\begin{array}{l}1 \mathrm{M} \mathrm{LiPF} 6 \text { in } \\
\mathrm{DEC/EC/DMC}\end{array}$ & $\begin{array}{l}\text { at } 3.5 \mathrm{mAh} \mathrm{cm-2} \mathrm{over} 88 \% \text { capacity } \\
\text { retention for } 200 \text { cycles. }\end{array}$ & {$[108]$} \\
\hline
\end{tabular}

\subsubsection{Diels-Alder Reaction based self-healing systems}

Rajeev et al. reported created a crosslinked polymer network based on 1,6-bismaleimide (BMI) as a crosslinker for furfurylamine-functional poly(acrylic acid) (FPAA) and then thermal Diels-Alder (DA) click chemistry, which was used as a new polymer for Silicon binding. The cross-linked network of Diels-Alder chemistry exhibited self-healing with Diels-Alder chemistry. The Si electrode with the Diels-Alder binder recorded high coulombic efficiency of $99.7 \%$ after 200 cycles. The Diels-Alder-PAA binder that shown in figure 14, outperformed commercially available silicone binders such as PAA, CMC, SA and PVdF with its 3D network structure and self-healing [22]. 


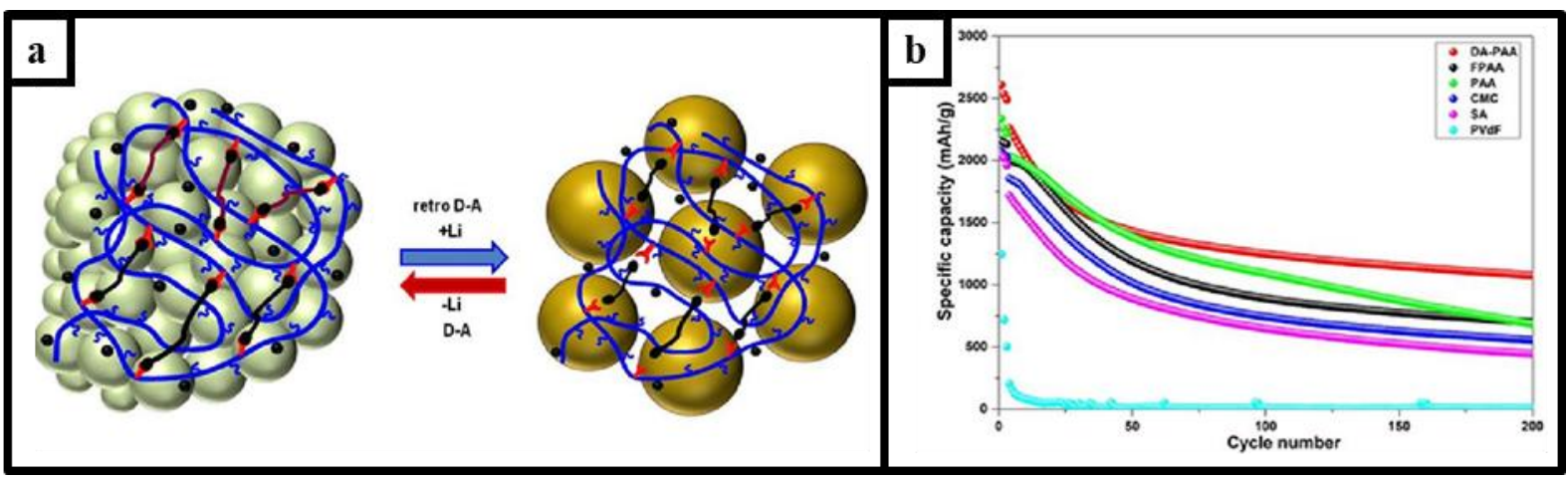

Figure 14. a. Diels-Alder chemistry in Silicon anode with self healing binder b. The comparison cycle-capacity with other binders, Reprinted with permission from 22, Copyright 2021, Advanced Materials

Table 9. Some self-healing materials for disulfide bonded interactions self-healing mechanism

\begin{tabular}{|l|l|l|l|l|}
\hline Self-healing material & $\begin{array}{l}\text { Anode Active } \\
\text { materials }\end{array}$ & Electrolyte & Electrochemical performance & Ref. \\
\hline 1,6-bismaleimide (BMI) & Silicon powder 50 & $1 \mathrm{M} \mathrm{LiPF}_{6}$ in EC/EMC & $1076 \mathrm{mAh} / \mathrm{g}$ efficiency of 99.7\%, & {$[22]$} \\
functionalized poly(acrylic & $\mathrm{nm}$ & $1: 2(\mathrm{v} / \mathrm{v})$ with 10\% FEC & After 200 cycles at 1C & \\
acid) (FPAA) DA-PAA & & & & \\
\hline
\end{tabular}

\section{Conclusion}

Self-healing materials have been investigated from electronics to the building industry and the biomedical fields. In addition to these areas, the application of self-healing materials to electrochemical-based devices such as batteries and supercapacitors is rapidly increasing. Concerning self-healing systems, many researches are also being performed in the manufacture of other electronic and electrochemical devices such as dielectric actuators and electrochemical sensors. Conducting polymers are very important for actuators, solar cells, sensors and energy storage devices. However, damage to these materials causes serious problems in device performance. The main requirement in the development of self-healing and conductive materials is to maintain a high conductivity level after damage. The most basic strategy for producing selfhealing conductors is to add dynamic reversible bonds to conductive polymers. There are many researches in the literature.

Sensors are widely used in our daily life to detect external signals, which are chemical or physical signals. Most mobile devices (such as cell phones, tablets, and laptops) have capacitive electric 
touchscreens. However, they are quite fragile in cases where accidental dropping or scratching causes the touch sensor to malfunction. The idea that if self-healing sensors are used, it could potentially increase the lifespan of such devices, especially for functional and aesthetic purposes, has increased research in this area.

Supercapacitors are promising energy storage devices that attract attention due to their fast chargedischarge rates, long life cycles, and high power densities. There are important studies in the literature to develop supercapacitors with high flexibility and lightness. However, deformation or breakage from stress or mechanical damage limits reliability and shortens the life of supercapacitors. The use of self-healing materials in the manufacture of supercapacitors is considered a good alternative for restoring electrical properties after mechanical damage.

In conclusion, although promising developments have been achieved so far, innovative materials strategies are still needed at the application level of self-healing materials and tools for practical use and eventual commercialization.

\section{References}

1. Wang, S.; Urban, M. W., Self-healing polymers. Nature Reviews Materials 2020, 5, (8), 562583.

2. Imato, K.; Nishihara, M.; Kanehara, T.; Amamoto, Y.; Takahara, A.; Otsuka, H., Self-Healing of Chemical Gels Cross-Linked by Diarylbibenzofuranone-Based Trigger-Free Dynamic Covalent Bonds at Room Temperature. Angewandte Chemie International Edition 2012, 51, (5), 1138-1142.

3. Wool, R. P., Self-healing materials: a review. Soft Matter 2008, 4, (3), 400-418.

4. Taskin, O. S.; Hubble, D.; Zhu, T.; Liu, G., Biomass-derived polymeric binders in silicon anodes for battery energy storage applications. Green Chemistry 2021, 23, (20), 7890-7901.

5. Zhao, Y.; Zhang, Y.; Sun, H.; Dong, X.; Cao, J.; Wang, L.; Xu, Y.; Ren, J.; Hwang, Y.; Son, I. H.; Huang, X.; Wang, Y.; Peng, H., A Self-Healing Aqueous Lithium-Ion Battery. Angewandte Chemie International Edition 2016, 55, (46), 14384-14388.

6. Urban, M. W.; Davydovich, D.; Yang, Y.; Demir, T.; Zhang, Y.; Casabianca, L., Key-andlock commodity self-healing copolymers. Science 2018, 362, (6411), 220-225.

7. Mai, W.; Yu, Q.; Han, C.; Kang, F.; Li, B., Self-Healing Materials for Energy-Storage Devices. Advanced Functional Materials 2020, 30, (24), 1909912. 
8. Taskin, O. S.; Yuca, N.; Papavasiliou, J.; Avgouropoulos, G., Interconnected conductive gel binder for high capacity silicon anode for Li-ion batteries. Materials Letters 2020, 273, 127918.

9. Chen, H.; Wu, Z.; Su, Z.; Chen, S.; Yan, C.; Al-Mamun, M.; Tang, Y.; Zhang, S., A mechanically robust self-healing binder for silicon anode in lithium ion batteries. Nano Energy 2021, 81, 105654.

10. Taskin, O. S.; Kiskan, B.; Weber, J.; Yagci, Y., One-Pot, One-Step Strategy for the Preparation of Clickable Melamine Based Microporous Organic Polymer Network. Macromolecular Materials and Engineering 2015, 300, (11), 1116-1122.

11. Huang, S.; Ren, J.; Liu, R.; Bai, Y.; Li, X.; Huang, Y.; Yue, M.; He, X.; Yuan, G., Low addition amount of self-healing ionomer binder for Si/graphite electrodes with enhanced cycling. New Journal of Chemistry 2018, 42, (9), 6742-6749.

12. Güzel, E.; Koçyiğit, Ü. M.; Taslimi, P.; Erkan, S.; Taskin, O. S., Biologically active phthalocyanine metal complexes: Preparation, evaluation of $\alpha$-glycosidase and anticholinesterase enzyme inhibition activities, and molecular docking studies. Journal of Biochemical and Molecular Toxicology 2021, 35, (6), e22765.

13. Taskin, O. S.; Kiskan, B.; Aksu, A.; Balkis, N.; Yagci, Y., Copper(II) removal from the aqueous solution using microporous benzidine-based adsorbent material. Journal of Environmental Chemical Engineering 2016, 4, (1), 899-907.

14. Qin, J.; Lin, F.; Hubble, D.; Wang, Y.; Li, Y.; Murphy, I. A.; Jang, S.-H.; Yang, J.; Jen, A. K. Y., Tuning self-healing properties of stiff, ion-conductive polymers. Journal of Materials Chemistry A 2019, 7, (12), 6773-6783.

15. Xu, Z.; Yang, J.; Zhang, T.; Nuli, Y.; Wang, J.; Hirano, S.-i., Silicon Microparticle Anodes with Self-Healing Multiple Network Binder. Joule 2018, 2, (5), 950-961.

16. Li, F.; Xu, J.; Hou, Z.; Li, M.; Yang, R., Silicon Anodes for High-Performance Storage Devices: Structural Design, Material Compounding, Advances in Electrolytes and Binders. ChemNanoMat 2020, 6, (5), 720-738.

17. Chen, D.; Wang, D.; Yang, Y.; Huang, Q.; Zhu, S.; Zheng, Z., Self-Healing Materials for Next-Generation Energy Harvesting and Storage Devices. Advanced Energy Materials 2017, 7, (23), 1700890. 
18. Luo, C.; Fan, X.; Ma, Z.; Gao, T.; Wang, C., Self-Healing Chemistry between Organic Material and Binder for Stable Sodium-Ion Batteries. Chem 2017, 3, (6), 1050-1062.

19. Yuca, N.; Cetintasoglu, M. E.; Dogdu, M. F.; Akbulut, H.; Tabanli, S.; Colak, U.; Taskin, O. S., Highly efficient poly(fluorene phenylene) copolymer as a new class of binder for highcapacity silicon anode in lithium-ion batteries. International Journal of Energy Research 2018, 42, (3), 1148-1157.

20. Wu, Z.-H.; Yang, J.-Y.; Yu, B.; Shi, B.-M.; Zhao, C.-R.; Yu, Z.-L., Self-healing alginatecarboxymethyl chitosan porous scaffold as an effective binder for silicon anodes in lithiumion batteries. Rare Metals 2019, 38, (9), 832-839.

21. Wang, Z.; Tao, F.; Pan, Q., A self-healable polyvinyl alcohol-based hydrogel electrolyte for smart electrochemical capacitors. Journal of Materials Chemistry A 2016, 4, (45), 1773217739.

22. Rajeev, K. K.; Nam, J.; Jang, W.; Kim, Y.; Kim, T.-H., Polysaccharide-based self-healing polymer binder via Schiff base chemistry for high-performance silicon anodes in lithium-ion batteries. Electrochimica Acta 2021, 384, 138364.

23. Bulut, E.; Güzel, E.; Yuca, N.; Taskin, O. S., Novel approach with polyfluorene/polydisulfide copolymer binder for high-capacity silicon anode in lithium-ion batteries. Journal of Applied Polymer Science 2020, 137, (4), 48303.

24. Ying, H.; Zhang, Y.; Cheng, J., Dynamic urea bond for the design of reversible and selfhealing polymers. Nature Communications 2014, 5, (1), 3218.

25. Xu, J. H.; Ye, S.; Ding, C. D.; Tan, L. H.; Fu, J. J., Autonomous self-healing supramolecular elastomer reinforced and toughened by graphitic carbon nitride nanosheets tailored for smart anticorrosion coating applications. Journal of Materials Chemistry A 2018, 6, (14), 58875898.

26. Xu, J.; Ye, S.; Fu, J., Novel sea cucumber-inspired material based on stiff, strong yet tough elastomer with unique self-healing and recyclable functionalities. Journal of Materials Chemistry A 2018, 6, (47), 24291-24297.

27. Li, X.; Zhang, H.; Zhang, P.; Yu, Y., A Sunlight-Degradable Autonomous Self-Healing Supramolecular Elastomer for Flexible Electronic Devices. Chemistry of Materials 2018, 30, (11), 3752-3758. 
28. Li, C.-H.; Wang, C.; Keplinger, C.; Zuo, J.-L.; Jin, L.; Sun, Y.; Zheng, P.; Cao, Y.; Lissel, F.; Linder, C.; You, X.-Z.; Bao, Z., A highly stretchable autonomous self-healing elastomer. Nature Chemistry 2016, 8, (6), 618-624.

29. Lopez, J.; Chen, Z.; Wang, C.; Andrews, S. C.; Cui, Y.; Bao, Z., The Effects of Cross-Linking in a Supramolecular Binder on Cycle Life in Silicon Microparticle Anodes. ACS Applied Materials \& Interfaces 2016, 8, (3), 2318-2324.

30. Kwon, T. w.; Choi, J. W.; Coskun, A., The Emerging Era of Supramolecular Polymeric Binders in Silicon Anodes. Chem. Soc. Rev. 2018, 47, 2145.

31. Frischmann, P. D.; Gerber, L. C.; Doris, S. E.; Tsai, E. Y.; Fan, F. Y.; Qu, X.; Jain, A.; Persson, K. A.; Chiang, Y. M.; Helms, B. A., Supramolecular Perylene Bisimide-Polysulfide Gel Networks as Nanostructured Redox Mediators in Dissolved Polysulfide Lithium-Sulfur Batteries. Chem. Mater. 2015, 27, 6765.

32. Cordier, P.; Tournilhac, F.; Soulié-Ziakovic, C.; Leibler, L., Self-Healing and Thermoreversible Rubber from Supramolecular Assembly. Nature 2008, 451, 977.

33. Fox, J.; Wie, J. J.; Greenland, B. W.; Burattini, S.; Hayes, W.; Colquhoun, H. M.; Mackay, M. E.; Rowan, S. J., High-strength, healable, supramolecular polymer nanocomposites. J Am Chem Soc 2012, 134, (11), 5362-8.

34. Burattini, S.; Colquhoun, H. M.; Greenland, B. W.; Hayes, W., A novel self-healing supramolecular polymer system. Faraday Discussions 2009, 143, (0), 251-264.

35. Shi, Y.; Wang, M.; Ma, C.; Wang, Y.; Li, X.; Yu, G., A Conductive Self-Healing Hybrid Gel Enabled by Metal-Ligand Supramolecule and Nanostructured Conductive Polymer. Nano Letters 2015, 15, (9), 6276-6281.

36. Ryu, J.; Kim, S.; Kim, J.; Park, S.; Lee, S.; Yoo, S.; Kim, J.; Choi, N.-S.; Ryu, J.-H.; Park, S., Room-Temperature Crosslinkable Natural Polymer Binder for High-Rate and Stable Silicon Anodes. Advanced Functional Materials 2020, 30, (9), 1908433.

37. Zhang, G.; Yang, Y.; Chen, Y.; Huang, J.; Zhang, T.; Zeng, H.; Wang, C.; Liu, G.; Deng, Y., A Quadruple-Hydrogen-Bonded Supramolecular Binder for High-Performance Silicon Anodes in Lithium-Ion Batteries. Small 2018, 14, (29).

38. Nam, J.; Kim, E.; K.K, R.; Kim, Y.; Kim, T.-H., A conductive self healing polymeric binder using hydrogen bonding for Si anodes in lithium ion batteries. Scientific Reports 2020, 10, (1), 14966. 
39. Cordier, P.; Tournilhac, F.; Soulié-Ziakovic, C.; Leibler, L., Self-healing and thermoreversible rubber from supramolecular assembly. Nature 2008, 451, (7181), 977-980.

40. Taskin, O. S.; Kiskan, B.; Yagci, Y., Polybenzoxazine Precursors As Self-Healing Agents for Polysulfones. Macromolecules 2013, 46, (22), 8773-8778.

41. Wang, C.; Wu, H.; Chen, Z.; McDowell, M. T.; Cui, Y.; Bao, Z., Self-healing chemistry enables the stable operation of silicon microparticle anodes for high-energy lithium-ion batteries. Nature Chemistry 2013, 5, (12), 1042-1048.

42. Yuca, N.; Taskin, O. S.; Arici, E., An overview on efforts to enhance the Si electrode stability for lithium ion batteries. Energy Storage n/a, (n/a), e94.

43. Alfaro, P.; Palavicini, A.; Wang, C., Hydrogen, Oxygen and Hydroxyl on Porous Silicon Surface: A Joint Density-Functional Perturbation Theory and Infrared Spectroscopy Approach. Thin Solid Films 2014, 571, 206.

44. Tasdelen, M. A.; Taskin, O. S.; Celik, C., Orthogonal Synthesis of Block Copolymer via Photoinduced CuAAC and Ketene Chemistries. Macromolecular Rapid Communications 2016, 37, (6), 521-526.

45. Lee, J. Y.; Buxton, G. A.; Balazs, A. C., Using nanoparticles to create self-healing composites. The Journal of Chemical Physics 2004, 121, (11), 5531-5540.

46. Gupta, S.; Zhang, Q.; Emrick, T.; Balazs, A.; Russell, T., Entropy-driven segregation of nanoparticles to cracks in multilayered composite polymer structures. Nature Materials 2006, 5, 229-233.

47. Brunsveld, L.; Folmer, B. J. B.; Meijer, E. W.; Sijbesma, R. P., Supramolecular Polymers. Chemical Reviews 2001, 101, (12), 4071-4098.

48. Harada, A.; Kobayashi, R.; Takashima, Y.; Hashidzume, A.; Yamaguchi, H., Macroscopic self-assembly through molecular recognition. Nat Chem 2011, 3, (1), 34-7.

49. Nakahata, M.; Takashima, Y.; Yamaguchi, H.; Harada, A., Redox-responsive self-healing materials formed from host-guest polymers. Nature Communications 2011, 2, (1), 511.

50. Kakuta, T.; Takashima, Y.; Nakahata, M.; Otsubo, M.; Yamaguchi, H.; Harada, A., Preorganized Hydrogel: Self-Healing Properties of Supramolecular Hydrogels Formed by Polymerization of Host-Guest-Monomers that Contain Cyclodextrins and Hydrophobic Guest Groups. Advanced Materials 2013, 25, (20), 2849-2853. 
51. Deng, G.; Tang, C.; Li, F.; Jiang, H.; Chen, Y., Covalent Cross-Linked Polymer Gels with Reversible Sol-Gel Transition and Self-Healing Properties. Macromolecules 2010, 43, (3), 1191-1194.

52. Nicolaÿ, R.; Kamada, J.; Van Wassen, A.; Matyjaszewski, K., Responsive Gels Based on a Dynamic Covalent Trithiocarbonate Cross-Linker. Macromolecules 2010, 43, (9), 4355-4361.

53. Amamoto, Y.; Kamada, J.; Otsuka, H.; Takahara, A.; Matyjaszewski, K., Repeatable Photoinduced Self-Healing of Covalently Cross-Linked Polymers through Reshuffling of Trithiocarbonate Units. Angewandte Chemie International Edition 2011, 50, (7), 1660-1663.

54. Reutenauer, P.; Buhler, E.; Boul, P. J.; Candau, S. J.; Lehn, J. M., Room temperature dynamic polymers based on Diels-Alder chemistry. Chemistry 2009, 15, (8), 1893-900.

55. Korth, M., Density Functional Theory: Not Quite the Right Answer for the Right Reason Yet. Angewandte Chemie International Edition 2017, 56, (20), 5396-5398.

56. Yan, B.; Huang, J.; Han, L.; Gong, L.; Li, L.; Israelachvili, J. N.; Zeng, H., Duplicating Dynamic Strain-Stiffening Behavior and Nanomechanics of Biological Tissues in a Synthetic Self-Healing Flexible Network Hydrogel. ACS Nano 2017, 11, (11), 11074-11081.

57. Nishimura, Y.; Chung, J.; Muradyan, H.; Guan, Z., Silyl Ether as a Robust and Thermally Stable Dynamic Covalent Motif for Malleable Polymer Design. Journal of the American Chemical Society 2017, 139, (42), 14881-14884.

58. Kovalenko, I.; Zdyrko, B.; Magasinski, A.; Hertzberg, B.; Milicev, Z.; Burtovyy, R.; Luzinov, I.; Yushin, G., A major constituent of brown algae for use in high-capacity Li-ion batteries. Science 2011, 334, (6052), 75-9.

59. Aslan, E.; Aksu, A.; Korkmaz, N. E.; Taskin, O. S.; Caglar, N. B., Monitoring the antioxidant activities by extracting the polyphenolic contents of algae collected from the Bosphorus. Marine Pollution Bulletin 2019, 141, 313-317.

60. Wang, C.; Wu, H.; Chen, Z.; McDowell, M. T.; Cui, Y.; Bao, Z., Self-healing chemistry enables the stable operation of silicon microparticle anodes for high-energy lithium-ion batteries. Nat Chem 2013, 5, (12), 1042-8.

61. Yue, L.; Zhang, L.; Zhong, H., Carboxymethyl Chitosan: A New Water Soluble Binder for Si Anode of Li-Ion Batteries. J. Power Sources 2014, 247, 327. 
62. Chen, Z.; Wang, C.; Lopez, J.; Lu, Z.; Cui, Y.; Bao, Z., High-Areal-Capacity Silicon Electrodes with Low-Cost Silicon Particles Based on Spatial Control of Self-Healing Binder. Advanced Energy Materials 2015, 5, (8), 1401826.

63. Sun, Y.; Lopez, J.; Lee, H. W.; Liu, N.; Zheng, G.; Wu, C. L.; Sun, J.; Liu, W.; Chung, J. W.; Bao, Z.; Cui, Y., A Stretchable Graphitic Carbon/Si Anode Enabled by Conformal Coating of a Self-Healing Elastic Polymer. Adv Mater 2016, 28, (12), 2455-61.

64. Gendensuren, B.; Oh, E.-S., Dual-crosslinked network binder of alginate with polyacrylamide for silicon/graphite anodes of lithium ion battery. Journal of Power Sources 2018, 384, 379386.

65. Ma, X.; Zou, S.; Tang, A.; Chen, L.; Deng, Z.; Pollet, B. G.; Ji, S., Three-dimensional hierarchical walnut kernel shape conducting polymer as water soluble binder for lithium-ion battery. Electrochimica Acta 2018, 269, 571-579.

66. Yang, J.; Zhang, L.; Zhang, T.; Wang, X.; Gao, Y.; Fang, Q., Self-healing strategy for Si nanoparticles towards practical application as anode materials for Li-ion batteries. Electrochemistry Communications 2017, 87.

67. Zhang, J.; Wang, N.; Zhang, W.; Fang, S.; Yu, Z.; Shi, B.; Yang, J., A cycling robust network binder for high performance $\mathrm{Si}$-based negative electrodes for lithium-ion batteries. Journal of Colloid and Interface Science 2020, 578, 452-460.

68. Hu, S.; Wang, L.; Huang, T.; Yu, A., A conductive self-healing hydrogel binder for highperformance silicon anodes in lithium-ion batteries. Journal of Power Sources 2020, 449, 227472.

69. Kim, D.; Hyun, S.; Han, S. M., Freestanding silicon microparticle and self-healing polymer composite design for effective lithiation stress relaxation. Journal of Materials Chemistry A 2018, 6, (24), 11353-11361.

70. Han, Z. J.; Yabuuchi, N.; Shimomura, K.; Murase, M.; Yui, H.; Komaba, S., High-Capacity Si-Graphite Composite Electrodes with a Self-Formed Porous Structure by a Partially Neutralized Polyacrylate for Li-ion Batteries. Energy Environ. Sci. 2012, 5, 9014.

71. Nguyen, M. H. T.; Oh, E. S., Application of a New Acrylonitrile/Butylacrylate Water-Based Binder for Negative Electrodes of Lithium-ion Batteries. Electrochem. Commun. 2013, 35, 45. 
72. Jeong, Y. K.; Kwon, T. w.; Lee, I.; Kim, T. S.; Coskun, A.; Choi, J. W., Hyperbranched $\beta$ Cyclodextrin Polymer as an Effective Multidimensional Binder for Silicon Anodes in Lithium Rechargeable Batteries. Nano Lett. 2014, 14, 864.

73. Chen, C.; Lee, S. H.; Cho, M.; Kim, J.; Lee, Y., Cross-Linked Chitosan as an Efficient Binder for Si Anode of Li-ion Batteries. ACS Appl. Mater. Interfaces 2016, 8, 2658.

74. Chen, H.; Ling, M.; Hencz, L.; Ling, H. Y.; Li, G.; Lin, Z.; Liu, G.; Zhang, S., Exploring Chemical, Mechanical, and Electrical Functionalities of Binders for Advanced EnergyStorage Devices. Chemical Reviews 2018, 118, (18), 8936-8982.

75. Yang, J.; Zhang, L.; Zhang, T.; Wang, X.; Gao, Y.; Fang, Q., Self-Healing Strategy for Si Nanoparticles Towards Practical Application as Anode Materials for Li-Ion Batteries. Electrochem. Commun. 2018, 87, 22.

76. Deshpande, R.; Li, J.; Cheng, Y.-T.; Verbrugge, M., Liquid Metal Alloys as Self-Healing Negative Electrodes for Lithium Ion Batteries. Journal of The Electrochemical Society 2011, 158, A845-A849.

77. Han, B.; Yang, Y.; Shi, X.; Zhang, G.; Gong, L.; Xu, D.; Zeng, H.; Wang, C.; Gu, M.; Deng, Y., Spontaneous repairing liquid metal/Si nanocomposite as a smart conductive-additive-free anode for lithium-ion battery. Nano Energy 2018, 50, 359-366.

78. Shi, Y.; Song, M.; Zhang, Y.; Zhang, C.; Gao, H.; Niu, J.; Ma, W.; Qin, J.; Zhang, Z., A selfhealing $\mathrm{CuGa} 2$ anode for high-performance Li ion batteries. Journal of Power Sources 2019, 437, 226889.

79. Jeong, Y. K.; Choi, J. W., Mussel-Inspired Self-Healing Metallopolymers for Silicon Nanoparticle Anodes. ACS Nano 2019, 13, (7), 8364-8373.

80. Zhang, L.; Zhang, L.; Chai, L.; Xue, P.; Hao, W.; Zheng, H., A Coordinatively Cross-Linked Polymeric Network as a Functional Binder for High-Performance Silicon Submicro-Particle Anodes in Lithium-ion Batteries. J. Mater. Chem. A 2014, 2, 19036.

81. Yoon, J.; Oh, D. X.; Jo, C.; Lee, J.; Hwang, D. S., Improvement of Desolvation and Resilience of Alginate Binders for Si-Based Anodes in a Lithium Ion Battery by Calcium-Mediated Cross-Linking. Phys. Chem. Chem. Phys. 2014, 16, 25628.

82. Kwon, T. w.; Jeong, Y. K.; Deniz, E.; AlQaradawi, S. Y.; Choi, J. W.; Coskun, A., Dynamic Cross-Linking of Polymeric Binders Based on Host-Guest Interactions for Silicon Anodes in Lithium Ion Batteries. ACS Nano 2015, 9, 11317. 
83. Kwon, T. w.; Jeong, Y. K.; Lee, I.; Kim, T. S.; Choi, J. W.; Coskun, A., Systematic MolecularLevel Design of Binders Incorporating Meldrum's Acid for Silicon Anodes in Lithium Rechargeable Batteries. Adv. Mater. 2014, 26, 7979.

84. Zeng, W.; Wang, L.; Peng, X.; Liu, T.; Jiang, Y.; Qin, F.; Hu, L.; Chu, P. K.; Huo, K.; Zhou, Y., Enhanced Ion Conductivity in Conducting Polymer Binder for High-Performance Silicon Anodes in Advanced Lithium-ion Batteries. Adv. Energy Mater. 2018, 8, 1702314.

85. Lim, S.; Chu, H.; Lee, K.; Yim, T.; Kim, Y. J.; Mun, J.; Kim, T. H., Physically Cross-Linked Polymer Binder Induced by Reversible Acid-Base Interaction for High-Performance Silicon Composite Anodes. ACS Appl. Mater. Interfaces 2015, 7, 23545.

86. Kim, S.; Jeong, Y. K.; Wang, Y.; Lee, H.; Choi, J. W., A “Sticky” Mucin-Inspired DNAPolysaccharide Binder for Silicon and Silicon-Graphite Blended Anodes in Lithium-Ion Batteries. Advanced Materials 2018, 30, (26), 1707594.

87. Ezeigwe, E. R.; Dong, L.; Manjunatha, R.; Tan, M.; Yan, W.; Zhang, J., A review of selfhealing electrode and electrolyte materials and their mitigating degradation of Lithium batteries. Nano Energy 2021, 84, 105907.

88. Kim, S.-M.; Jeon, H.; Shin, S.-H.; Park, S.-A.; Jegal, J.; Hwang, S. Y.; Oh, D. X.; Park, J., Superior Toughness and Fast Self-Healing at Room Temperature Engineered by Transparent Elastomers. Advanced Materials 2018, 30, (1), 1705145.

89. Engle, L. P.; Wagener, K. B., A Review of Thermally Controlled Covalent Bond Formation in Polymer Chemistry. Journal of Macromolecular Science, Part C 1993, 33, (3), 239-257.

90. Kennedy, J. P.; Castner, K. F., Thermally reversible polymer systems by cyclopentadienylation. II. The synthesis of cyclopentadiene-containing polymers. Journal of Polymer Science: Polymer Chemistry Edition 1979, 17, (7), 2055-2070.

91. Chen, X.; Dam, M. A.; Ono, K.; Mal, A.; Shen, H.; Nutt, S. R.; Sheran, K.; Wudl, F., A thermally re-mendable cross-linked polymeric material. Science 2002, 295, (5560), 1698-702.

92. Lee, D. H.; Heo, G.; Pyo, K.-h.; Kim, Y.; Kim, J.-W., Mechanically Robust and Healable Transparent Electrode Fabricated via Vapor-Assisted Solution Process. ACS Applied Materials \& Interfaces 2016, 8, (12), 8129-8136.

93. Pyo, K.-h.; Lee, D. H.; Kim, Y.; Kim, J.-W., Extremely rapid and simple healing of a transparent conductor based on Ag nanowires and polyurethane with a Diels-Alder network. Journal of Materials Chemistry C 2016, 4, (5), 972-977. 
94. Canadell, J.; Goossens, H.; Klumperman, B., Self-Healing Materials Based on Disulfide Links. Macromolecules 2011, 44, (8), 2536-2541.

95. Tobolsky, A.; MacKnight, W.; Takahashi, M., Relaxation of disulfide and tetrasulfide polymers. The Journal of Physical Chemistry 1964, 68, (4), 787-790.

96. Takahashi, Y.; Tobolsky, A. V., Chemorheological Study on Natural Rubber Vulcanizates. Polymer Journal 1971, 2, (4), 457-467.

97. Tesoro, G. C.; Sastri, V., Reversible crosslinking in epoxy resins. I. Feasibility studies. Journal of Applied Polymer Science 1990, 39, (7), 1425-1437.

98. Sastri, V. R.; Tesoro, G. C., Reversible crosslinking in epoxy resins. II. New approaches. Journal of Applied Polymer Science 1990, 39, (7), 1439-1457.

99. Tsarevsky, N. V.; Matyjaszewski, K., Reversible redox cleavage/coupling of polystyrene with disulfide or thiol groups prepared by atom transfer radical polymerization. Macromolecules 2002, 35, (24), 9009-9014.

100.Kuhl, N.; Bode, S.; Bose, R. K.; Vitz, J.; Seifert, A.; Hoeppener, S.; Garcia, S. J.; Spange, S.; van der Zwaag, S.; Hager, M. D.; Schubert, U. S., Acylhydrazones as Reversible Covalent Crosslinkers for Self-Healing Polymers. Advanced Functional Materials 2015, 25, (22), 32953301.

101.Montarnal, D.; Capelot, M.; Tournilhac, F.; Leibler, L., Silica-Like Malleable Materials from Permanent Organic Networks. Science 2011, 334, 965.

102.Yu, K.; Taynton, P.; Zhang, W.; Dunn, M. L.; Qi, H. J., Influence of stoichiometry on the glass transition and bond exchange reactions in epoxy thermoset polymers. RSC Advances 2014, 4, (89), 48682-48690.

103.Belowich, M. E.; Stoddart, J. F., Dynamic imine chemistry. Chemical Society Reviews 2012, 41, (6), 2003-2024.

104.Chao, A.; Negulescu, I.; Zhang, D., Dynamic covalent polymer networks based on degenerative imine bond exchange: tuning the malleability and self-healing properties by solvent. Macromolecules 2016, 49, (17), 6277-6284.

105.Cao, P.-F.; Yang, G.; Li, B.; Zhang, Y.; Zhao, S.; Zhang, S.; Erwin, A.; Zhang, Z.; Sokolov, A. P.; Nanda, J.; Saito, T., Rational Design of a Multifunctional Binder for High-Capacity Silicon-Based Anodes. ACS Energy Letters 2019, 4, (5), 1171-1180. 
106.K.K, R.; Nam, J.; Kim, E.; Kim, Y.; Kim, T.-H., A self-healable polymer binder for Si anodes based on reversible Diels-Alder chemistry. Electrochimica Acta 2020, 364, 137311.

107.Jung, C. H.; Kim, K. H.; Hong, S. H., Stable Silicon Anode for Lithium-Ion Batteries through Covalent Bond Formation with a Binder via Esterification. ACS Appl Mater Interfaces 2019, 11, (30), 26753-26763.

108.Jiao, X.; Yin, J.; Xu, X.; Wang, J.; Liu, Y.; Xiong, S.; Zhang, Q.; Song, J., Highly EnergyDissipative, Fast Self-Healing Binder for Stable Si Anode in Lithium-Ion Batteries. Advanced Functional Materials 2021, 31, (3), 2005699.

109.Jiao, Y.; Chen, W.; Lei, T.; Dai, L.; Chen, B.; Wu, C.; Xiong, J., A Novel Polar Copolymer Design as a Multi-Functional Binder for Strong Affinity of Polysulfides in Lithium-Sulfur Batteries. Nanoscale Res. Lett. 2017, 12, 195. 